\title{
Ritual, Recycling and Recontextualisation:
}

\section{Putting the Concealed Shoe into Context}

\begin{abstract}
The concealed shoe is shrouded in mystery. All we know for certain is that a large number of shoes were concealed in various locations within buildings, and that this practice was particularly popular in England during the $18^{\text {th }}$ and $19^{\text {th }}$ centuries. Other than these few facts, all other information we may read on the subject is speculation. With no contemporaneous written sources on this practice, we must rely on archaeological evidence in order to ascertain the motivations behind the act of concealment. An analysis of two case-studies of concealed shoe caches from North Yorkshire proves invaluable in this investigation, together with an examination of the relevant folk beliefs of the period. It will also be questioned where the concealed shoe stands in relation to archaeological classificatory systems. As a marginal, mutable object, it renders many of the popular dichotomies redundant, calling into question the pertinence of such categories as secular/sacred and valuable/rubbish, and the complex biographies of the concealed shoes - transitioning from practical footwear to numinous objects - also illuminates a wealth of recontextualisations, which I have dubbed 'ritual recycling'.
\end{abstract}




\section{Ritual, Recycling and Recontextualisation: \\ Putting the Concealed Shoe into Context}

\section{Introduction}

It was in the 1950s when June Swann, former Keeper of the Boot and Shoe Collection of Northampton Museum, first noticed a recurring pattern in the finds being donated to her department (Swann 1996: 56). A wide range of footwear, dating primarily from the eighteenth to the nineteenth centuries, was brought to her attention, having been discovered in unusual locations within buildings. It appeared that these shoes had been deliberately concealed, and Swann took it upon herself to gather as much data as possible on this unfamiliar, previously unstudied phenomenon. As the numbers of these finds multiplied, it became increasingly obvious that the concealing of shoes was a widespread practice. In 1969, Swann listed 129 such shoes; by 1986, the number had grown to 700 (Merrifield 1987: 133); and by 1996, 1100 such finds had been recorded, the vast majority of them found in England (figs. 1-2).

The evidently widespread practice of shoe concealment - despite having attracted a wealth of scholarly theories and modern interpretations - still, however, remains a mystery to us, simply because no contemporaneous written record has been found explaining the practice. Why were such shoes concealed and what were the concealers hoping to achieve? The subject of the concealed shoe is an enigma, challenging us to solve it, and it is this very mystery that makes concealment such an intriguing subject. With no written sources to utilise, it is in the realm of archaeology where we will find our answers; it is the shoes themselves that will offer the most useful testimony. Thus using the archaeological evidence, together with any relevant folkloric sources, we hope to unearth the motivations behind this seemingly illogical, mysterious practice. The core aim of this essay, therefore, is to use all of the means at our disposal, including two previously unstudied case-studies, in order to ascertain the purpose of these concealed shoes and to put them into context.

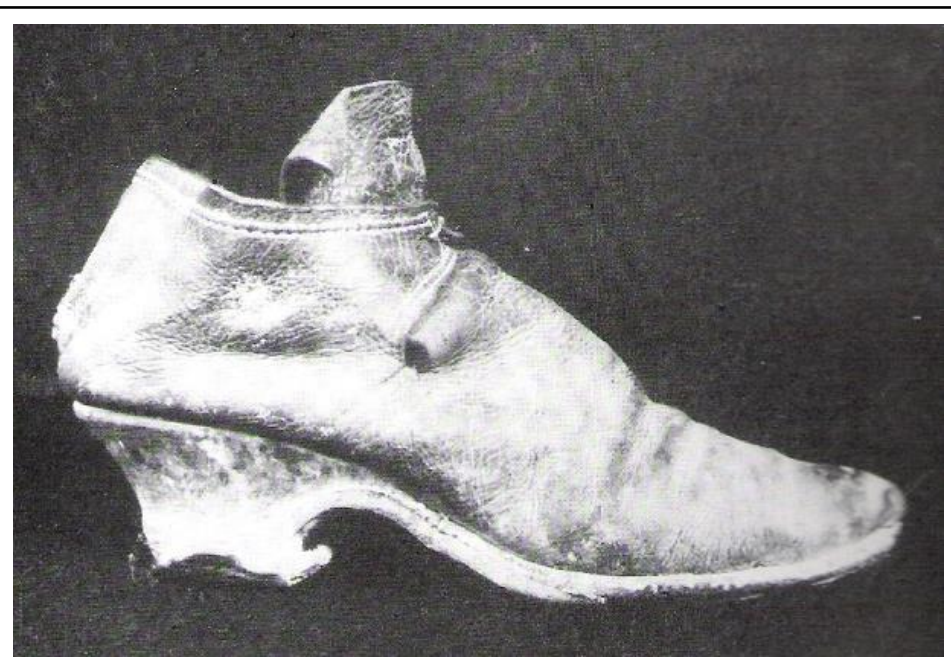

Figure 1 - Shoe discovered in fireplace, Corfe Castle, Dorset, c.1650-75. (From Merrifield 1987: fig. 42) 


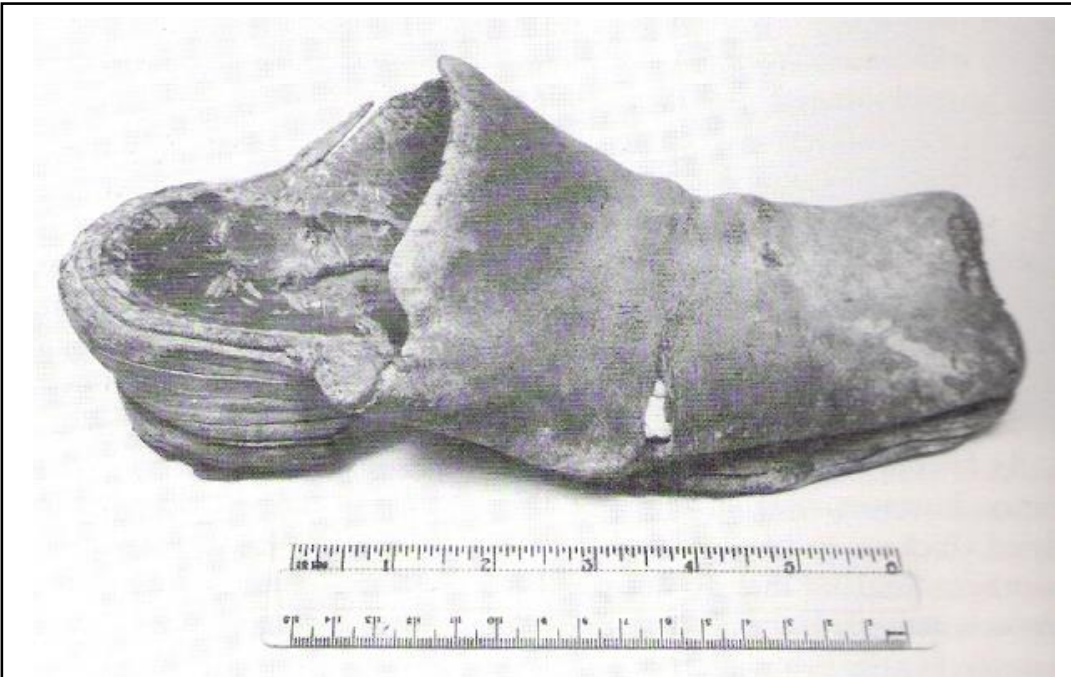

Figure 2 - Shoe found in chimney breast of cottage in Peaslake, Surrey, c.1670-80. (From Merrifield 1987: fig. 43)

\section{The Case-Studies}

Case-study 1 is from Ilkley; case-study 2, Otley. Both towns, only six miles apart, are situated in Wharfedale, North Yorkshire (fig. 3). In my choice of location, I hope to rectify the geographic biases so glaringly evident in previous studies. Such a focus on the southern counties of England, for which both Eastop and Merrifield are guilty, leads one to believe that shoe concealment was not practiced in the north. A map of Otley (fig. 4), highlighting the number of concealed shoes discovered in the town, should certainly put that misguided notion to rest.

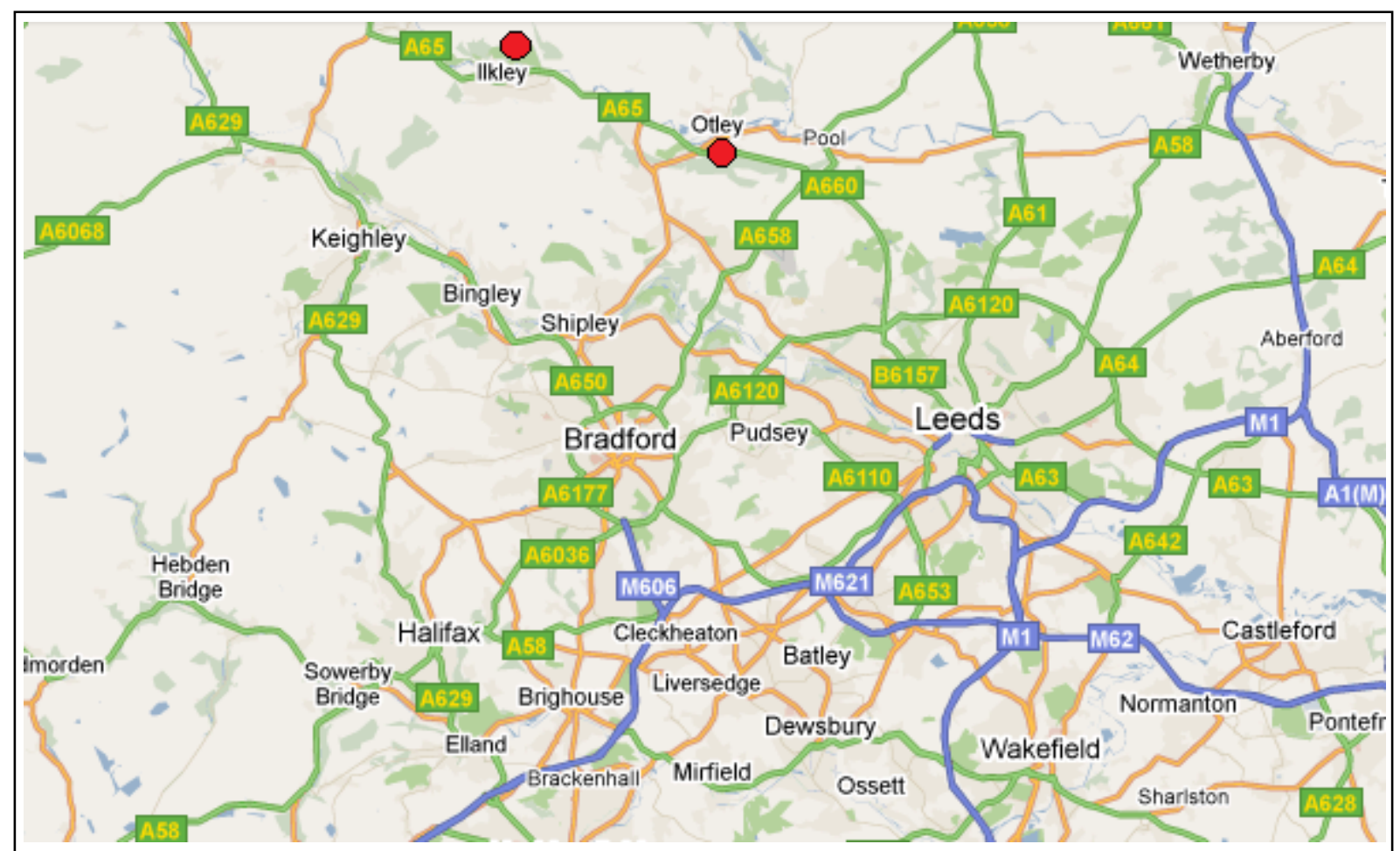

Figure 3 - Locations of case-studies in North Yorkshire. (Adapted from Google Maps) 


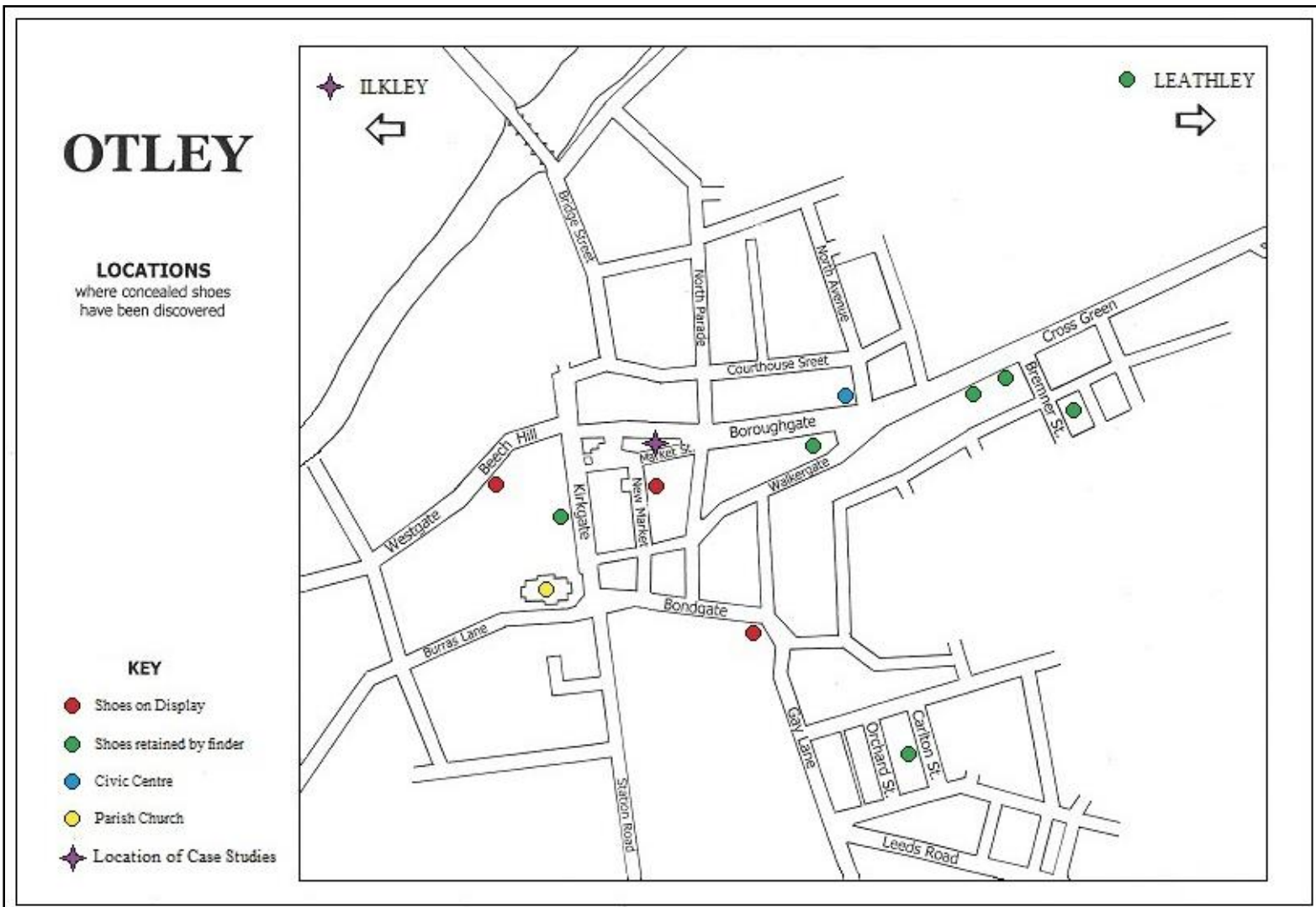

Figure 4 - Locations of concealed shoes in Otley. (Adapted from map provided by Otley Museum)

Two shoes were discovered at case-study 1 (fig. 5), a man's court shoe and a child's 'clog', concealed separately in Lane End Farmhouse, Middleton, Ilkley (fig. 6). Only one will be studied in this essay (hereafter ILKLEY 1). The building itself (fig. 7) is a late seventeenth-century farmhouse, part of the Middleton Estate, and according to the records compiled by Swann, 10.9\% of concealed shoes have been found in farm buildings (1996: 57), ${ }^{1}$ so this is certainly not atypical. Also in keeping with Swann's records are the dates of the shoes; both are of Victorian style and, as the graph below shows (fig. 8), the years between 1800 and 1899 were by the far the most popular for the practice of concealing shoes (Hoggard 1996: 65).

ILKLEY 1 (figs. 9-11) is a child's leather shoe (or 'clog'), with wooden soles and seven sets of eyelets. The shoe measures $17.4 \mathrm{~cm}$ in length, $6.2 \mathrm{~cm}$ in width at its widest point, and $8.9 \mathrm{~cm}$ in height at the heel. The condition of the shoe is old and worn, with a large hole in the toe. It appears to have been a straight shoe as was common for nineteenth-century children's shoes (Swann 1996: 65), but the emphasis of the wear on the left side implies that it may have been worn more often on the left foot. The leather upper is nailed onto a wooden sole, which is a common style for shoes that were

${ }^{1} 42.6 \%$ of concealed shoes were found in cottages, $26 \%$ in urban buildings, $10.9 \%$ in farm buildings, $9.4 \%$ in manor houses and mansions, the remaining in town halls, public houses, churches, etc. 
meant to be hard-wearing, and there are no adornments. This style of wooden-soled clog was particularly popular amongst the working classes in the northern counties of England during the eighteenth century, as Dr. Pococke wrote in his Travels through England (Cartwright 1887: 44-45), and it remained widespread throughout the $19^{\text {th }}$ century also, only fading out of use in Lancashire and Yorkshire at the beginning of the twentieth century (Riello 2006: 34). ILKLEY 1, therefore, probably dates to no later than 1900. It was discovered on a ledge up the chimney breast (fig. 12) by the farmhouse's previous owner in c. 1996.

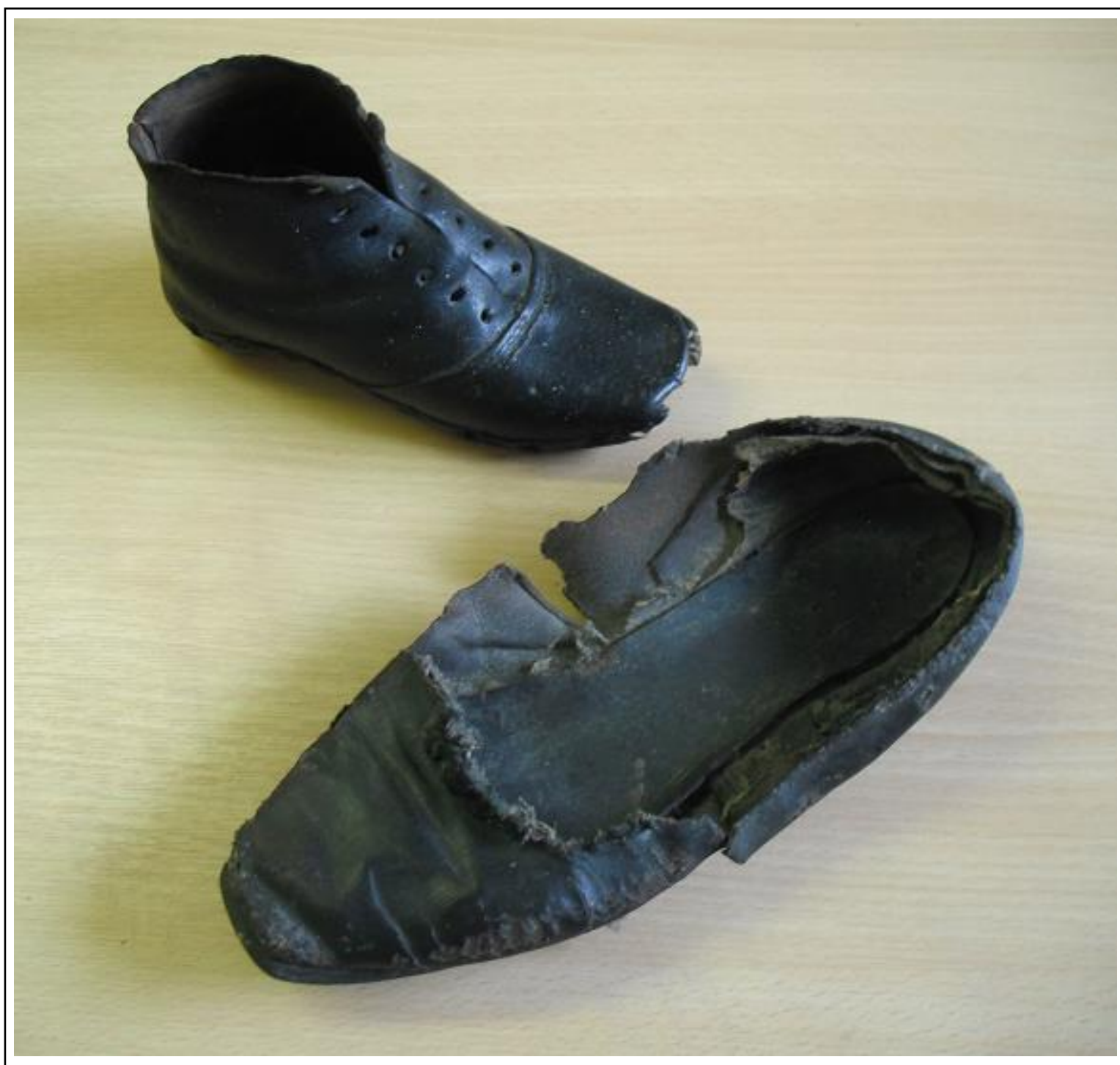

Figure 5 - Shoes found in Lane End Farmhouse, Ilkley. (Photograph by C. Houlbrook) 
Ceri Houlbrook

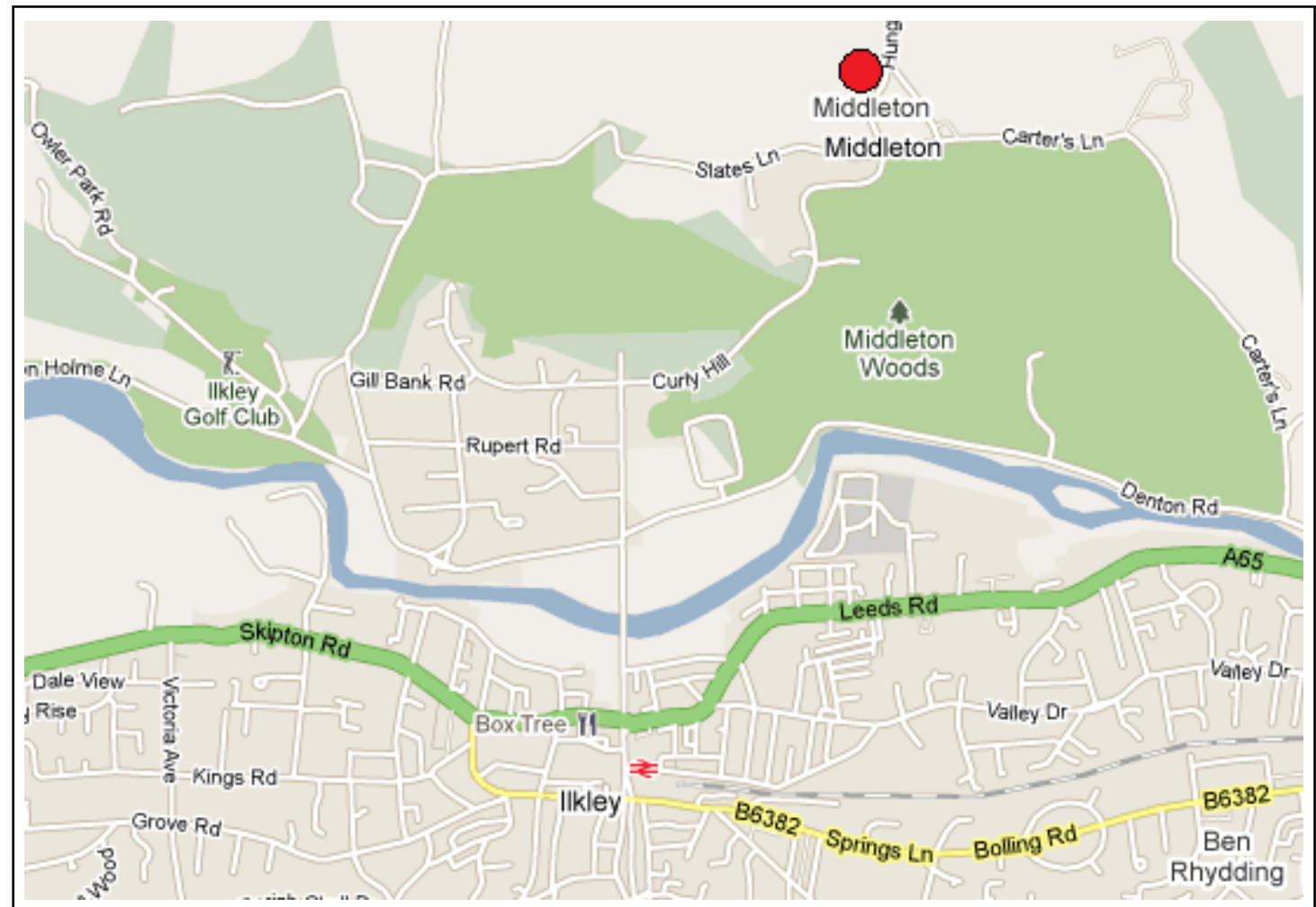

Figure 6 - Location of case-study 1, Ilkley. (Adapted from Google Maps)

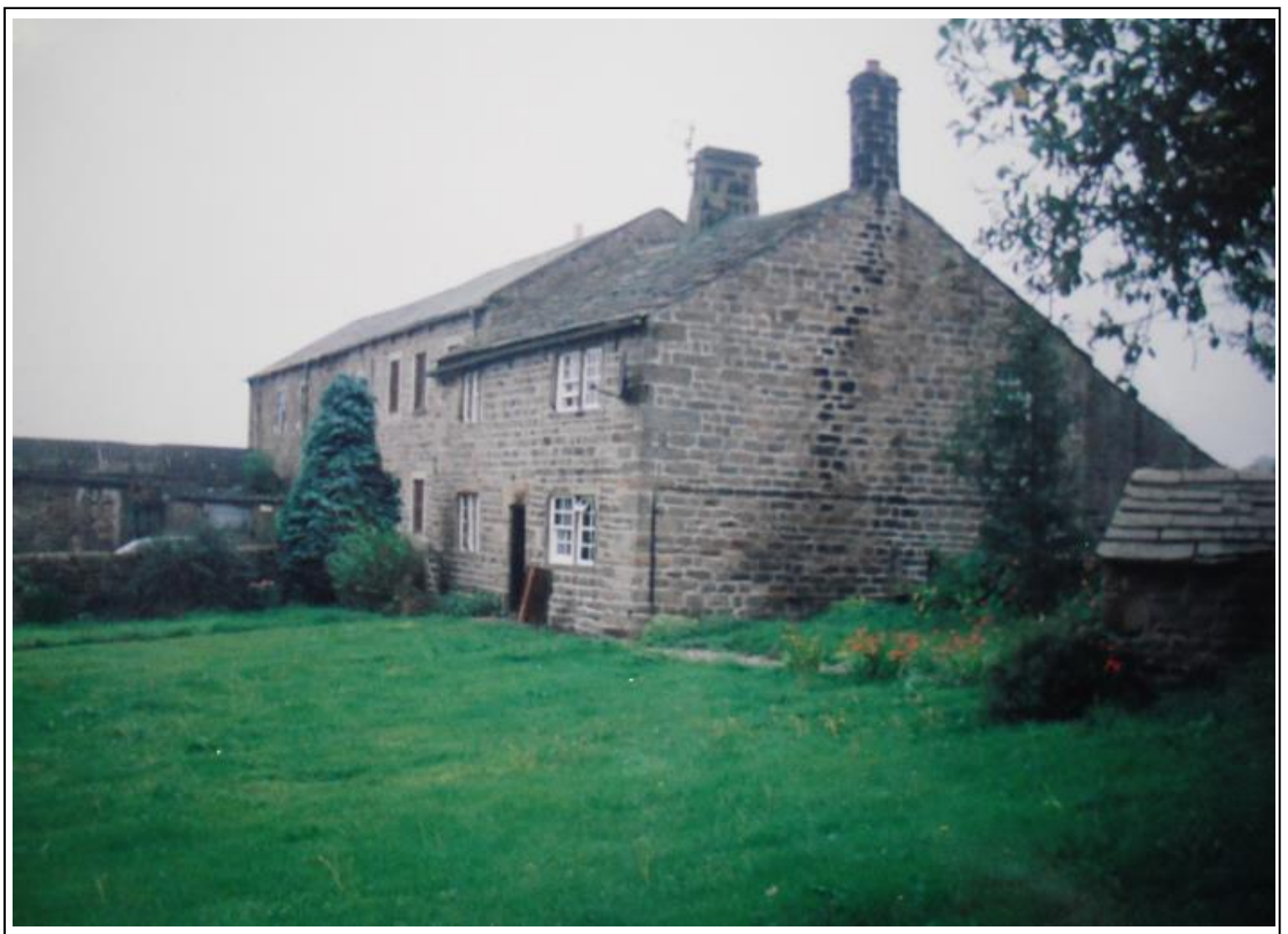

Figure 7 - Lane End Farmhouse, Ilkley. (Photograph by Kate Armitage) 


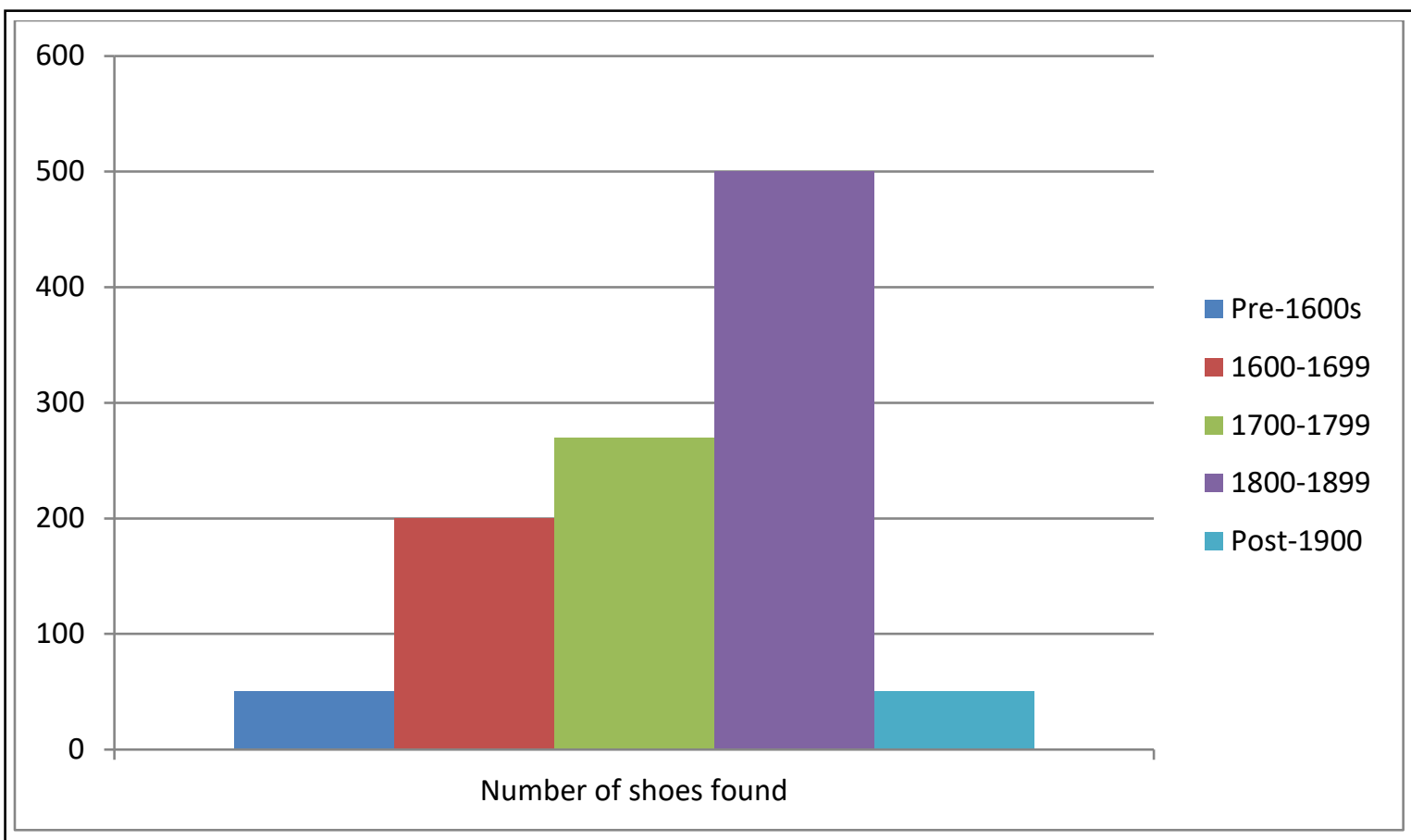

Figure 8 - Graph representing the dates of the shoes discovered. (Based on the figures provided by Hoggard 2004: 179)

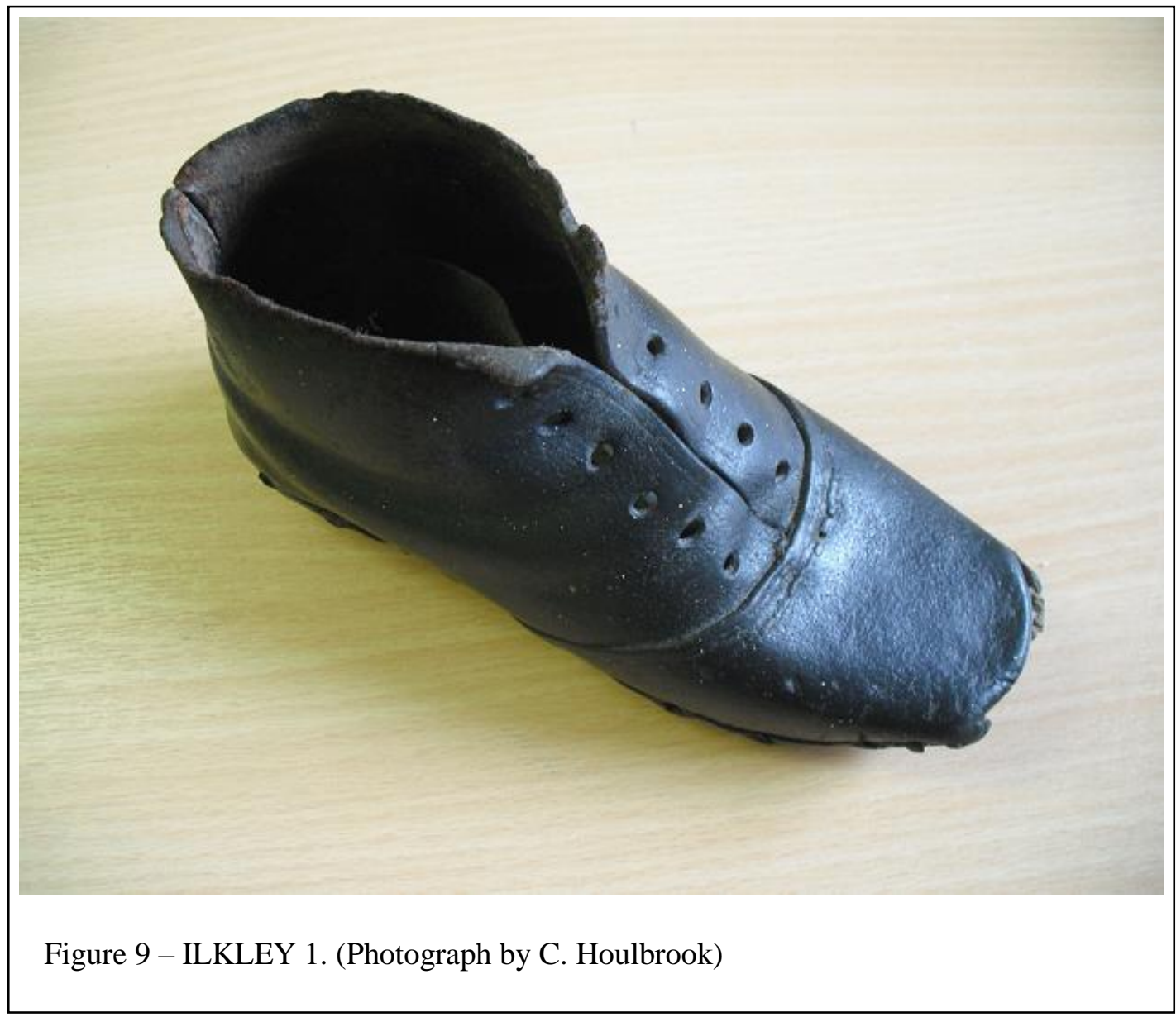




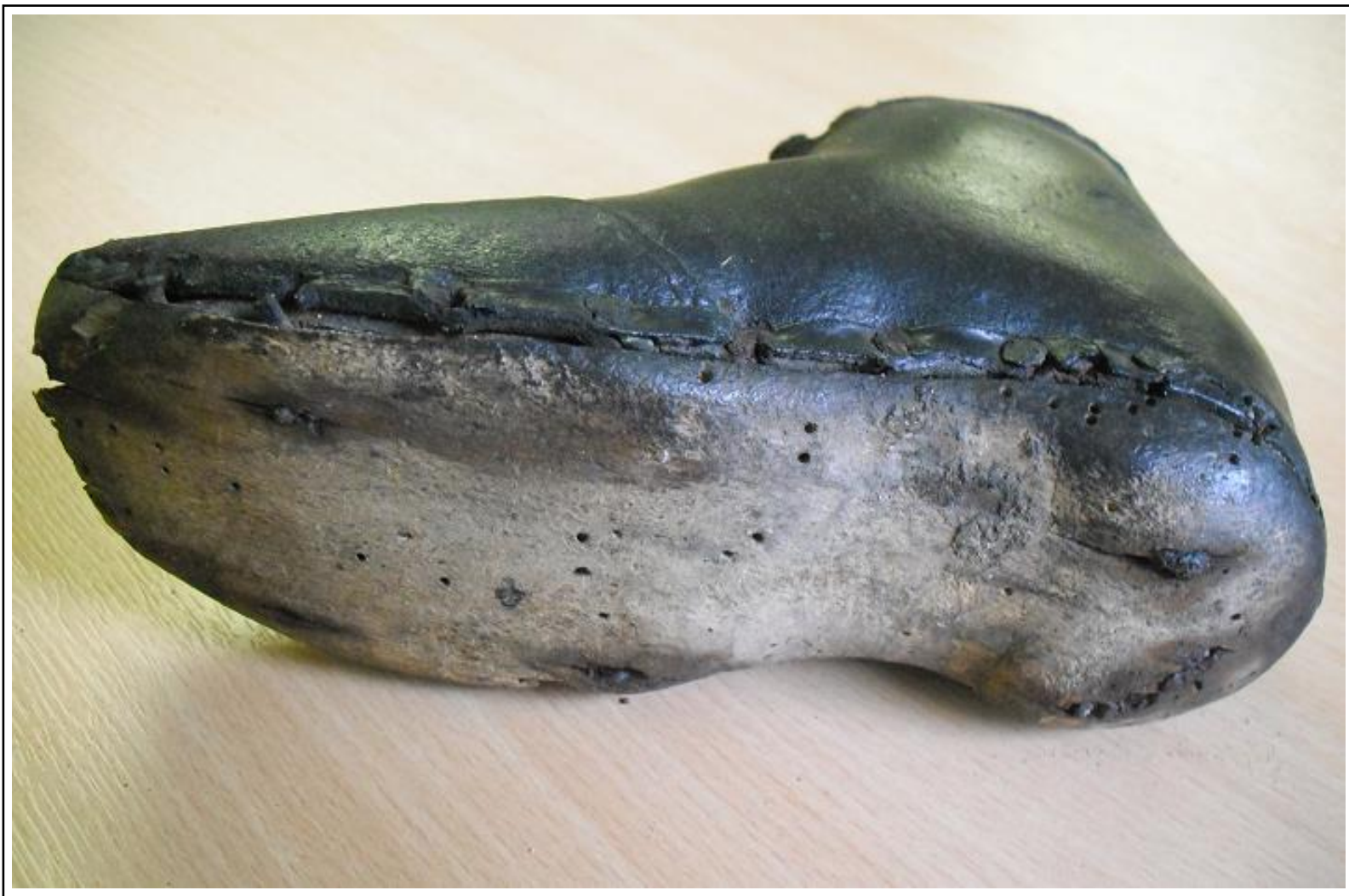

Figure 10 - ILKLEY 1. (Photograph by C. Houlbrook)

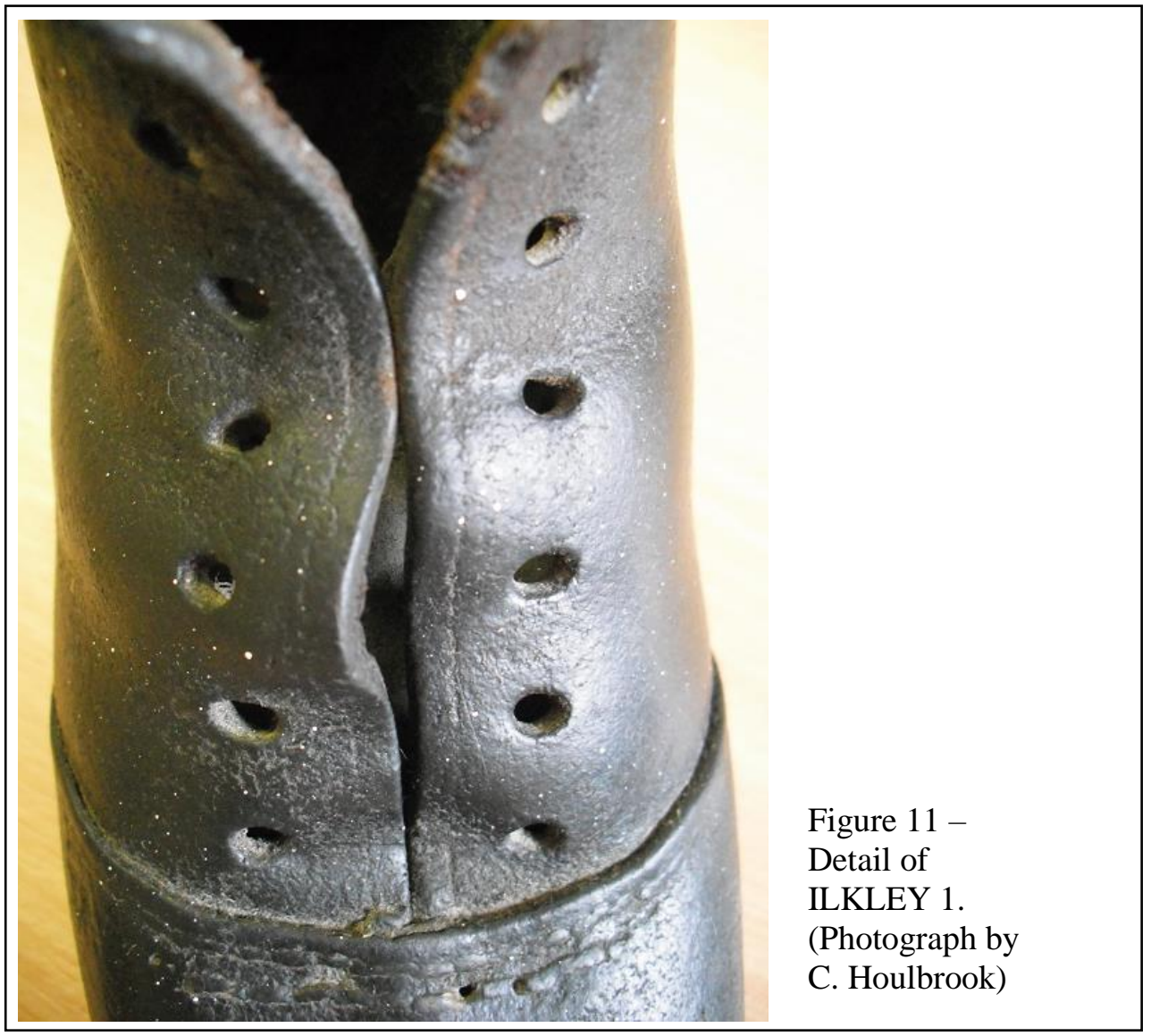




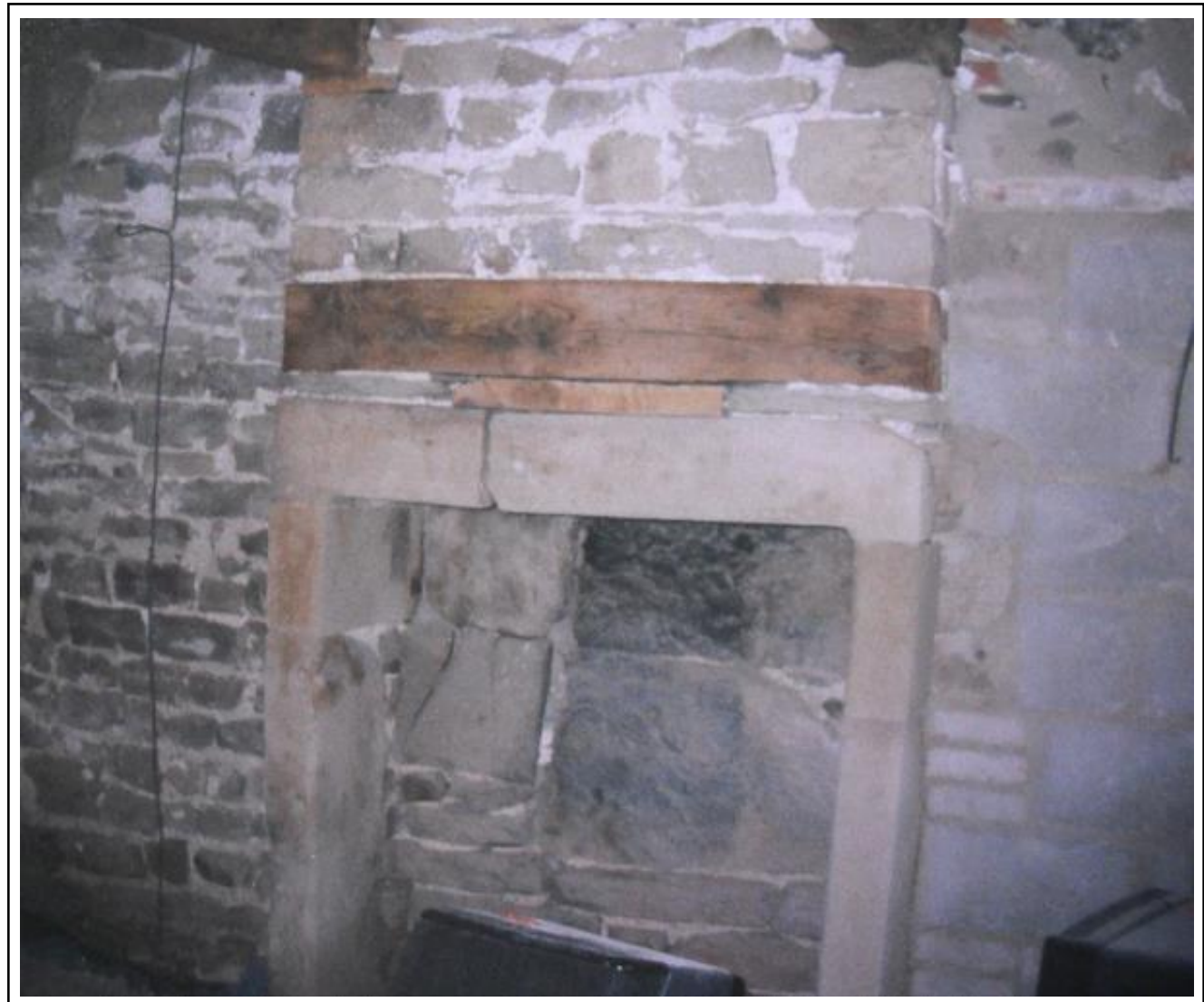

Figure 12 - Fireplace in which ILKLEY 1 was found. (Photograph by Kate Armitage)

The cache of case-study 2 was discovered in 1994 in the roof space of 2-4 Market Street, Otley (fig. 13). This building seems to have originally been a barn or workshop before the town's redevelopment in the seventeenth century. In the nineteenth century, the body of the building was removed when cellars were dug and the building enlarged, and as the shoes in this cache date mainly to the $1860 \mathrm{~s}$, perhaps they were concealed during this renovation. The cache consists of a family of five shoes (fig. 14): a child's shoe, a woman's button boot (fig. 15), a man's court shoe with a black cotton bow (fig. 16), a man's court shoe with a latchet tie front (fig. 17), and a lace-up boot. Records at Northampton Museum list at least 28 examples of footwear caches that include shoes of men, women and children, which Eastop terms 'families' (2006: 247), so it is certainly not uncommon to find such large caches of shoes concealed together. For this essay, however, only two shoes will be studied (hereafter OTLEY 1 and OTLEY 2).

OTLEY 1 (figs. 18-21) is a child's leather ankle-strap shoe. It measures $17.5 \mathrm{~cm}$ in length, $4.5 \mathrm{~cm}$ in width at its widest point, and $6.4 \mathrm{~cm}$ in height at the heel. The material is brown leather with no adornments, the condition is old and worn, and, like ILKLEY 1, it seems to have been a straight. The square-cut throat and the toe shape suggest that it was probably made in the 1860s, and the crudeness of the design implies that it was made for a working-class child, as do the numerous 
hobnails in the sole (fig. 19); Pehr Kalm, writing in 1748, observed that the shoes of labourers were 'strongly armed with iron... knocked full of nails under the middle of the sole...so that they can go with these a long time before they are worn out' (Lucas 1892: 244-245). OTLEY 1 was discovered in the roof space of a townhouse in Otley during renovations; the Keeper of the Otley Museum collection, Christine Dean, asked the builders to search for shoes while they were renovating. Unfortunately, they had already disposed of one, but after her enquiry, five more were discovered. ${ }^{2}$ OTLEY 1 was then donated to Otley Museum, where it was restored in 1994, catalogued as $\mathrm{O} / \mathrm{MP} / \mathrm{ft} / 1$, and placed into storage.

OTLEY 2 (figs. 22-24) was found under the same circumstances as OTLEY 1. It too was donated to Otley Museum in 1994, catalogued as O/MP/ft/5 and placed into storage, but, unlike the other four shoes of the cache, this shoe was left in its original state. Despite only the quarters and heel remaining, we can identify it as a lace-up boot, most likely a woman's, and probably also from the 1860s. The neat stitching on the heel appears to be the work of a sewing machine, and as the machine introduced for stitching boot uppers was not invented until 1857 (Harding 1934: 2), OTLEY 2 cannot have been made before this date. It appears to be a fairly standard working class shoe with hobnail repairs, but its condition remains in such a poor state that no other noteworthy aspects of it can be ascertained or described.

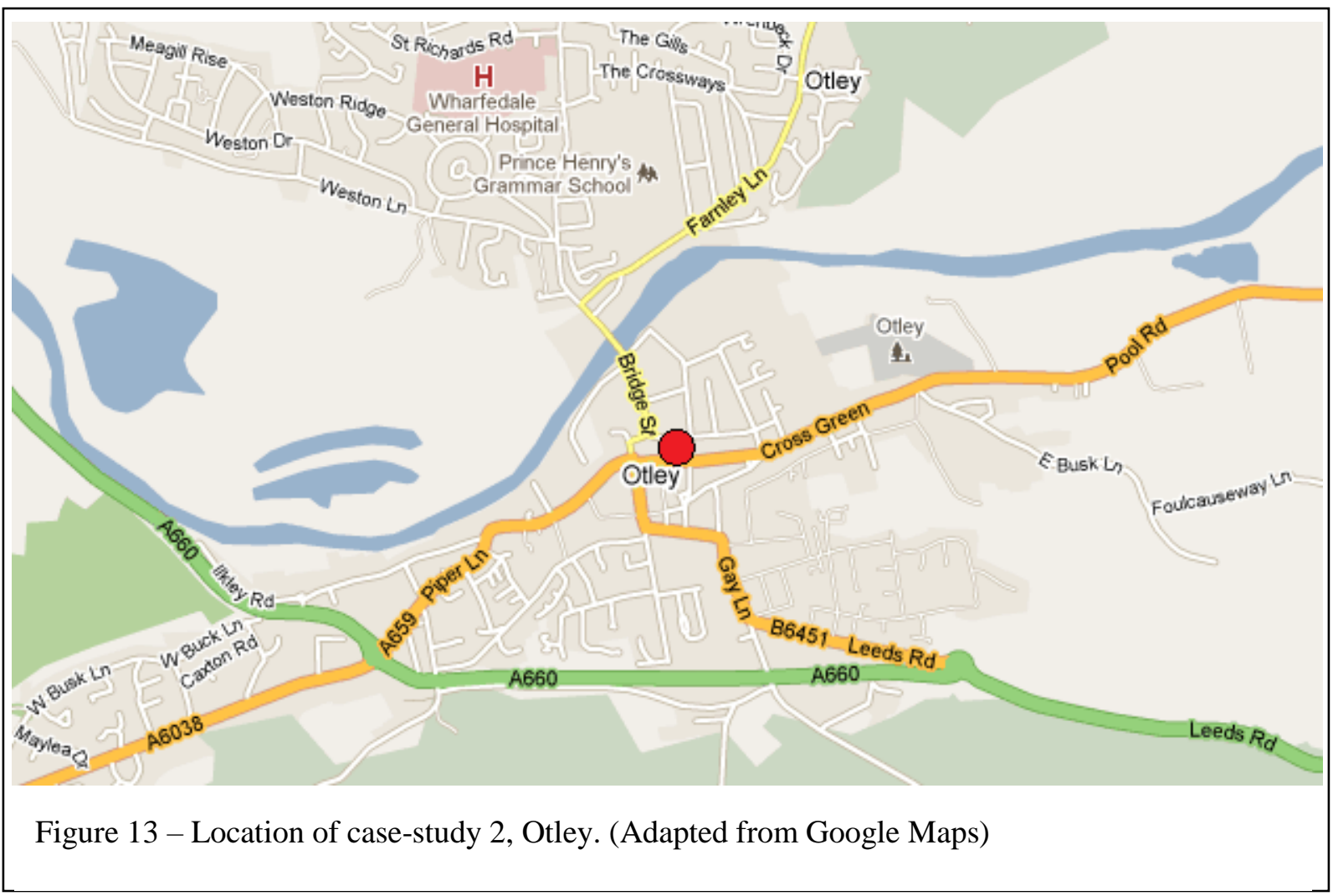

${ }^{2}$ Correspondence between Ms. Christine Dean and the Keeper at Northampton Museum, $14^{\text {th }}$ April, 1994 


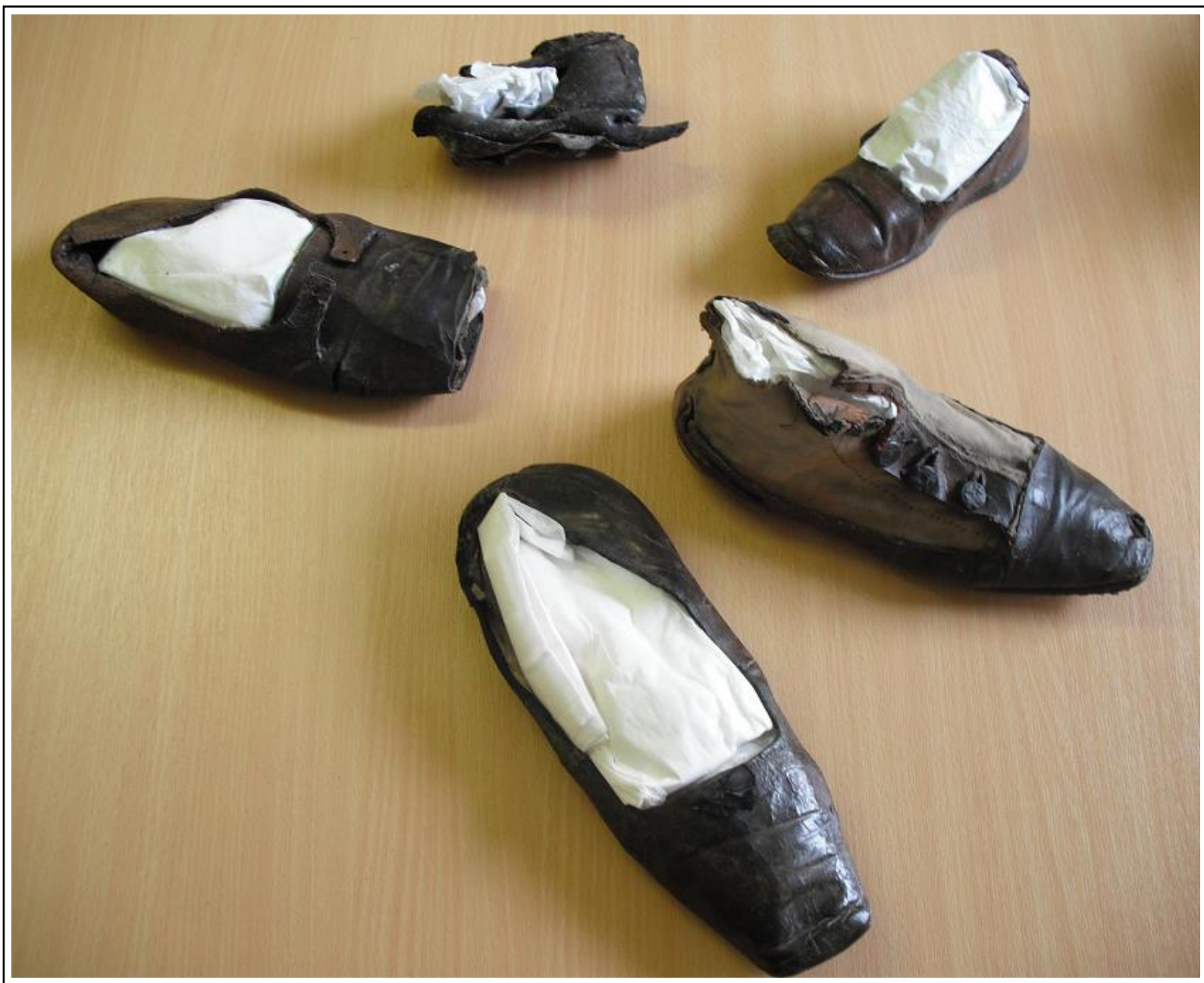

Figure 14 - Family of shoes (O/MP/ft/1-5), Otley. (Photograph by C. Houlbrook)

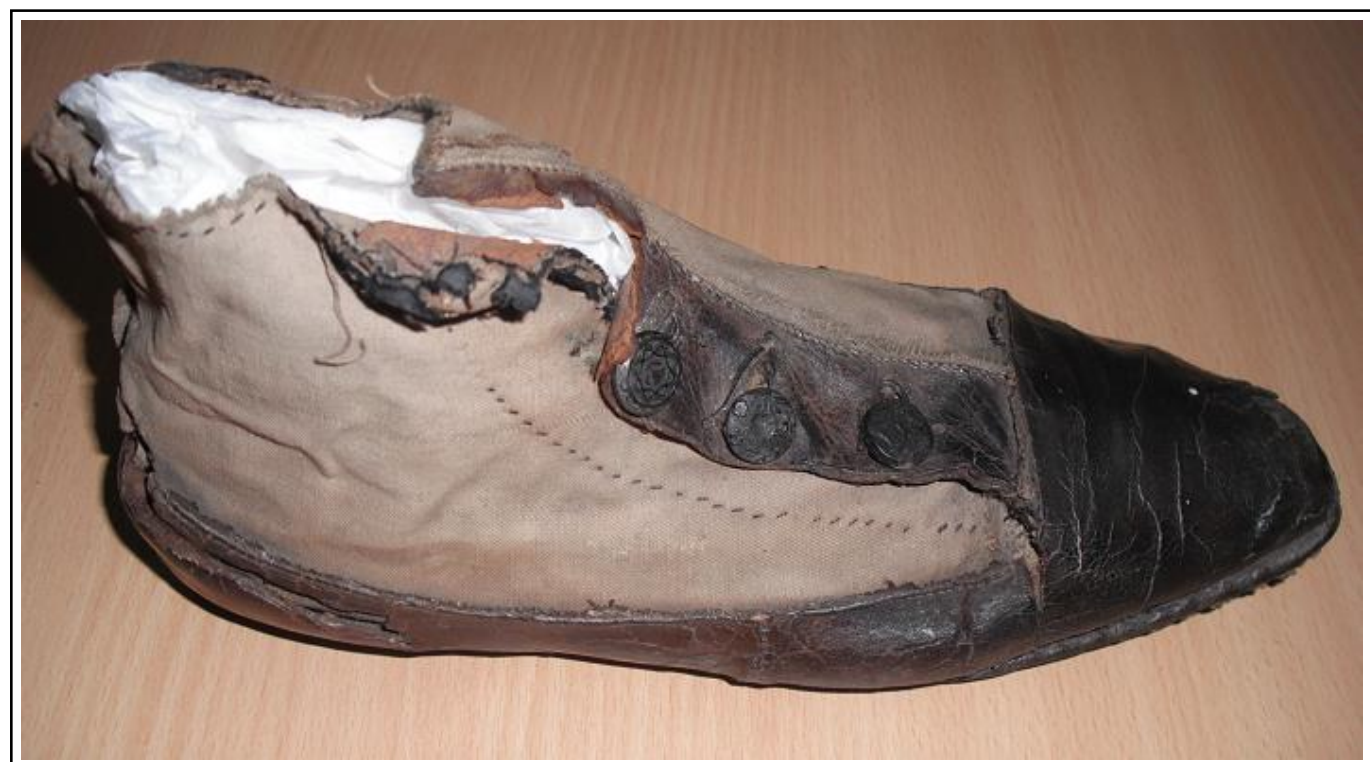

Figure $15-\mathrm{O} / \mathrm{MP} / \mathrm{ft} / 2$ - Woman's button boot, Otley. (Photograph by C. Houlbrook) 
Ceri Houlbrook
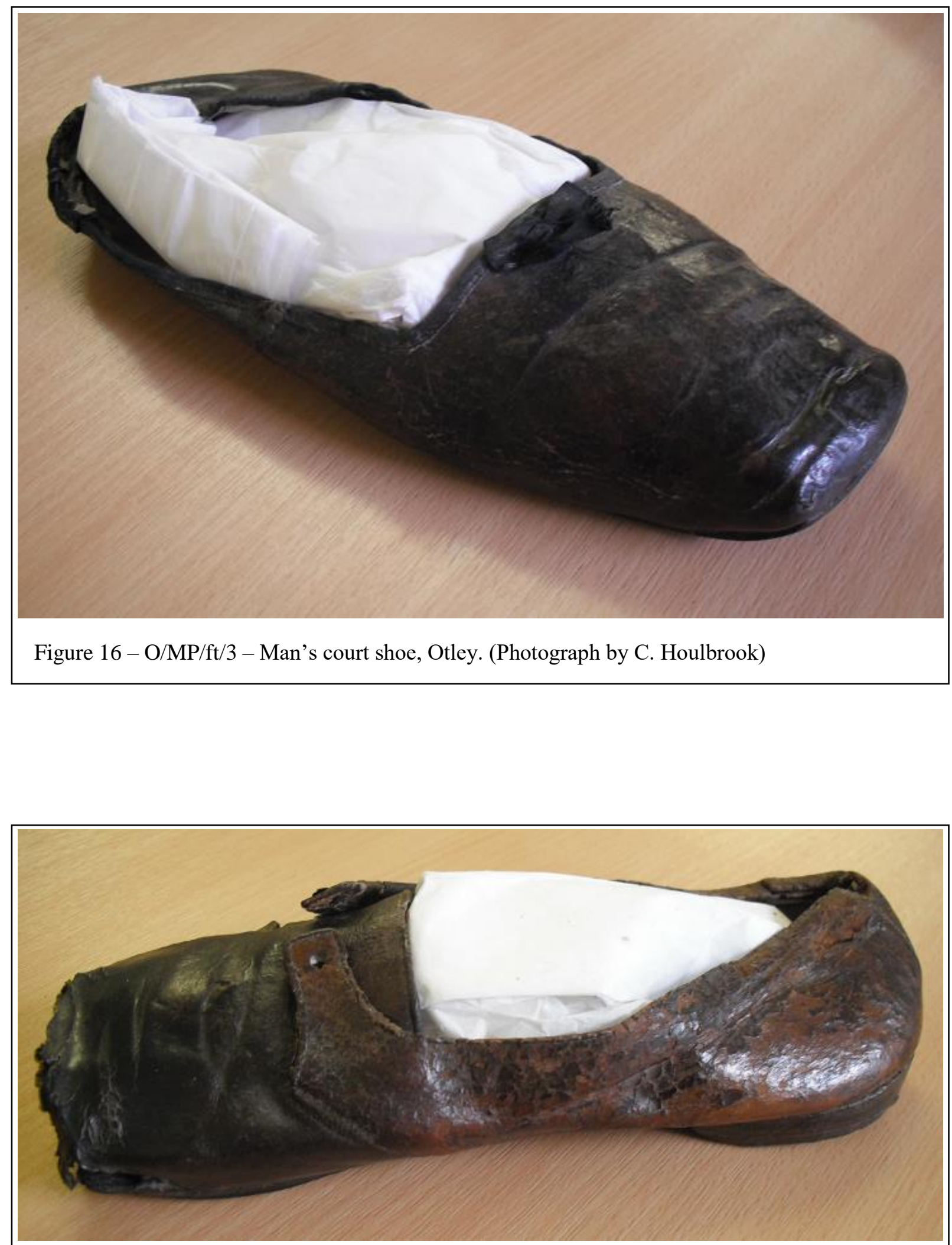

Figure $17-\mathrm{O} / \mathrm{MP} / \mathrm{ft} / 4$ - Man's shoe with latchet tie front, Otley. (Photograph by C. Houlbrook) 


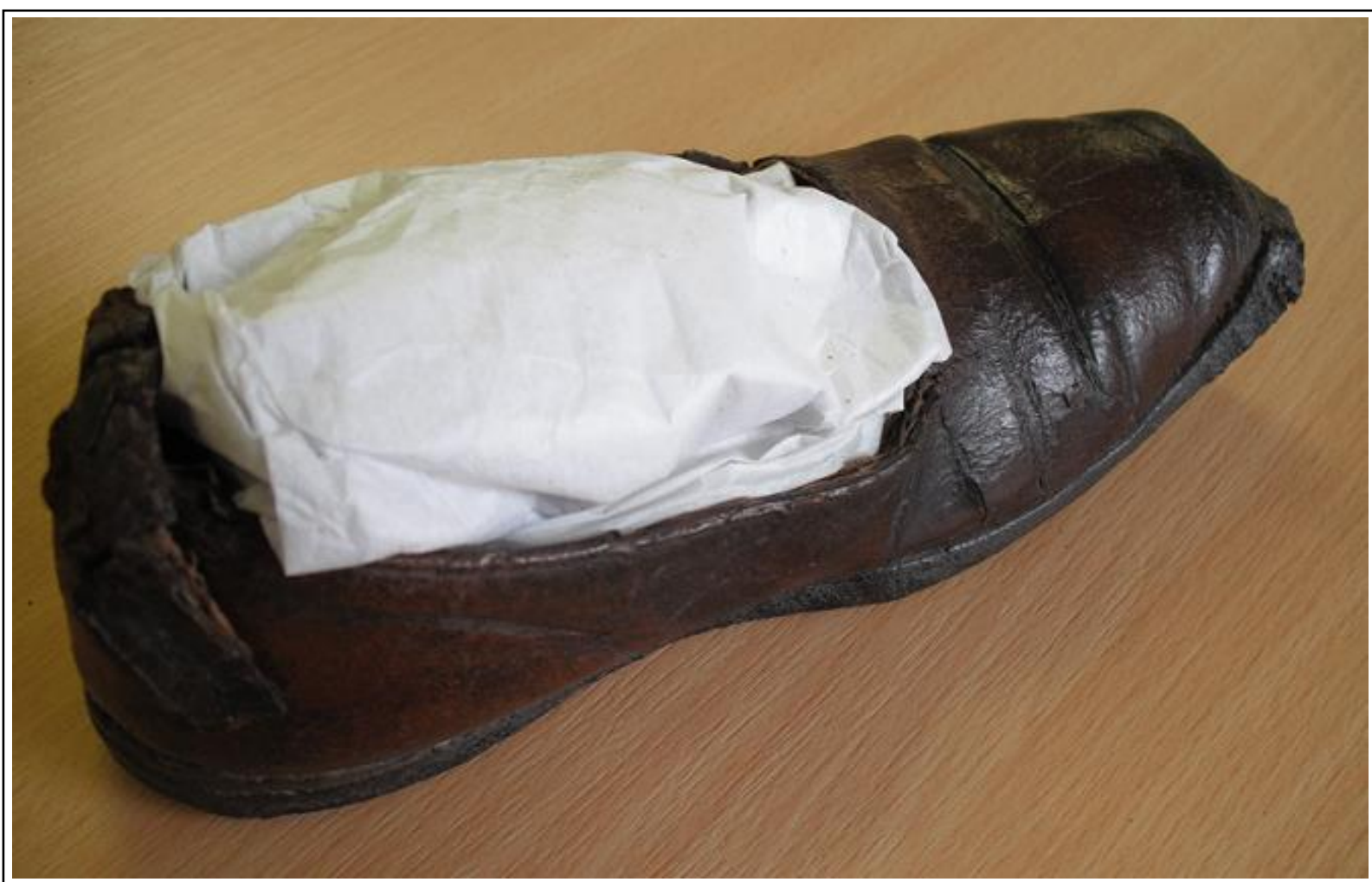

Figure 18 - OTLEY 1 - O/MP/ft/1 - Child's ankle strap shoe. (Photograph by C. Houlbrook)

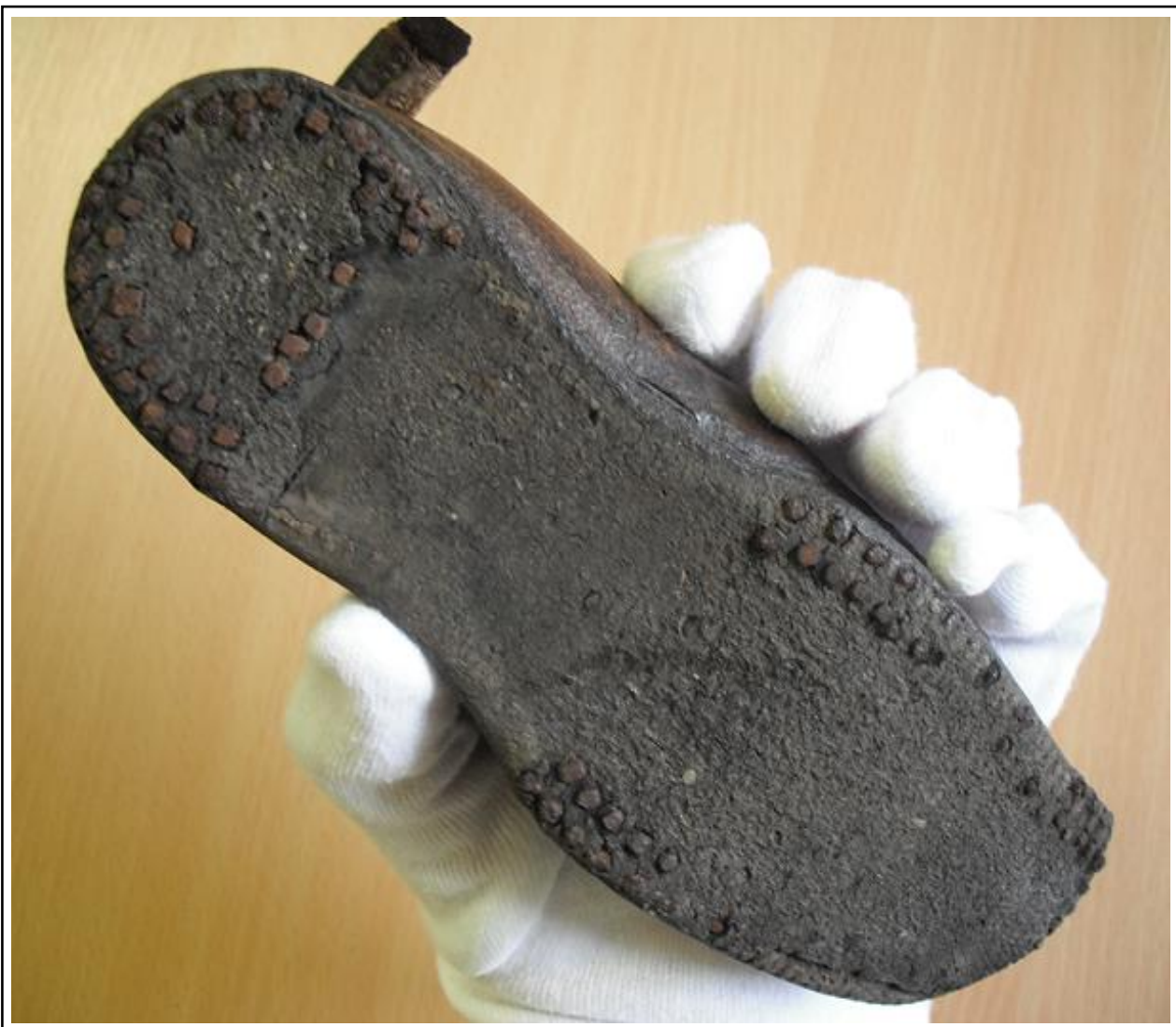

Figure 19 - Hobnailed sole of OTLEY 1. (Photograph by C. Houlbrook) 
Ceri Houlbrook

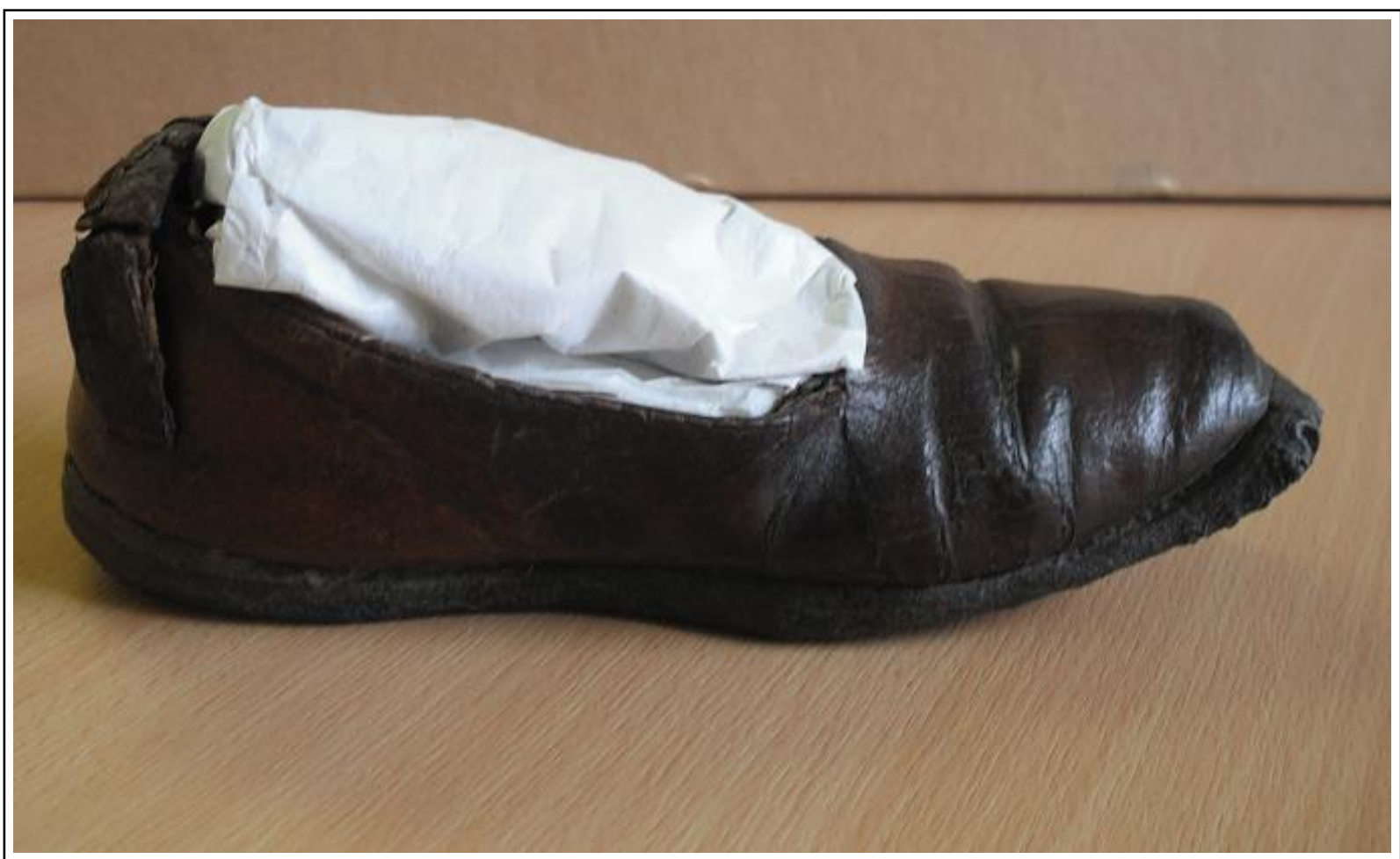

Figure 20 - OTLEY 1. (Photograph by C. Houlbrook)

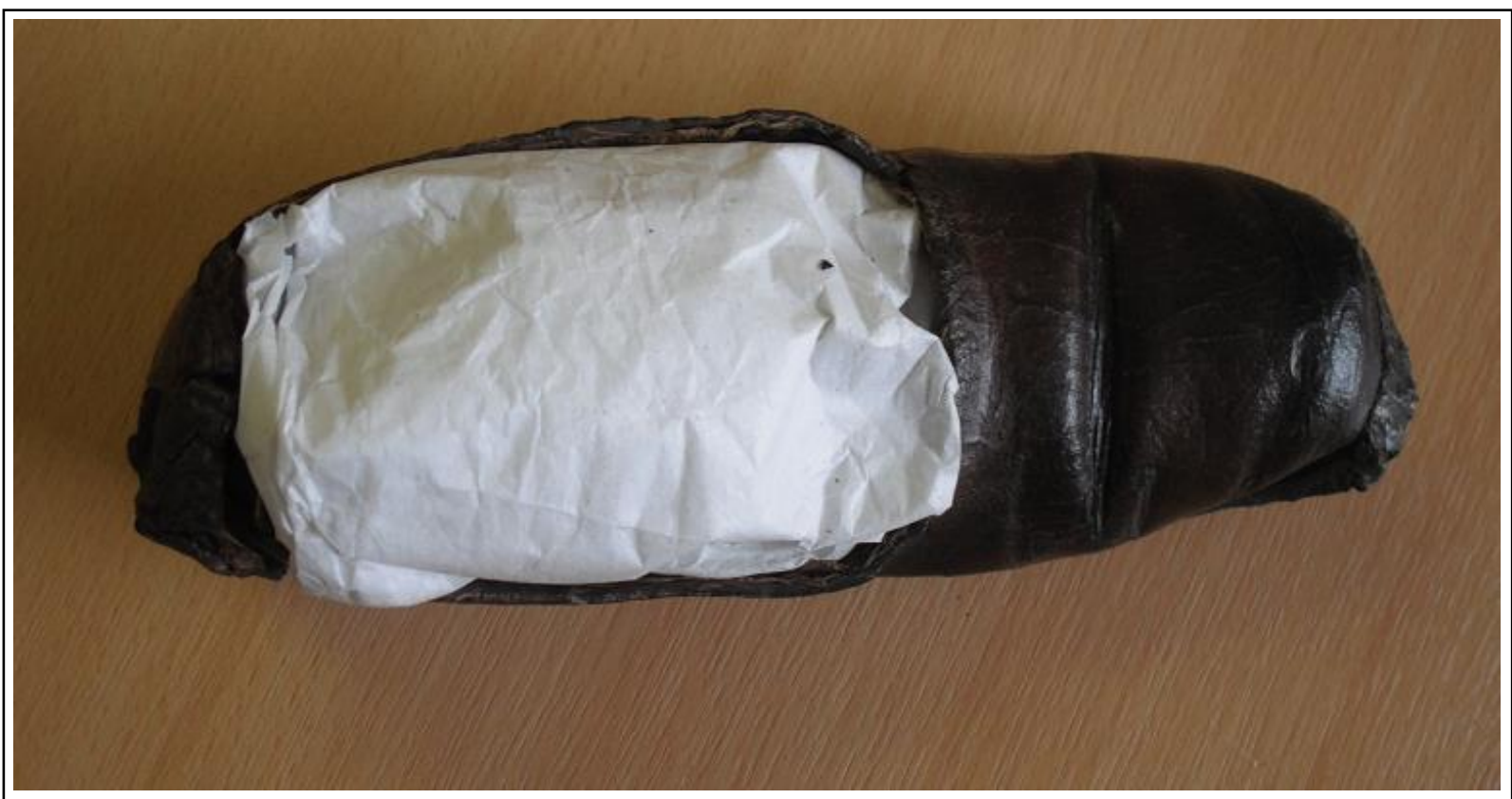

Figure 21 - OTLEY 1. (Photograph by C. Houlbrook) 
Ceri Houlbrook

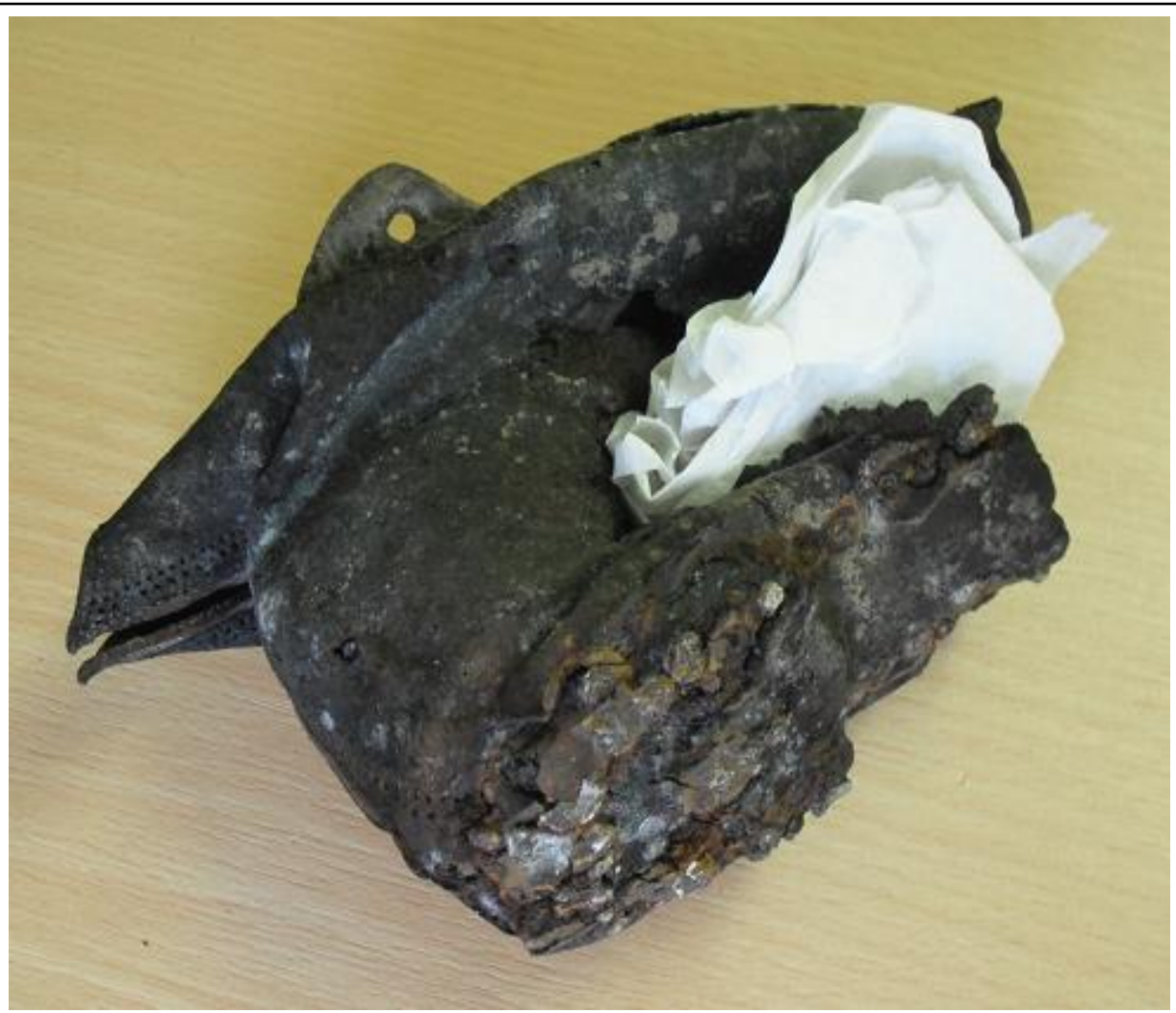

Figure 22 - OTLEY 2 - O/MP/ft/5 - Unrestored lace-up boot. (Photograph by C. Houlbrook)

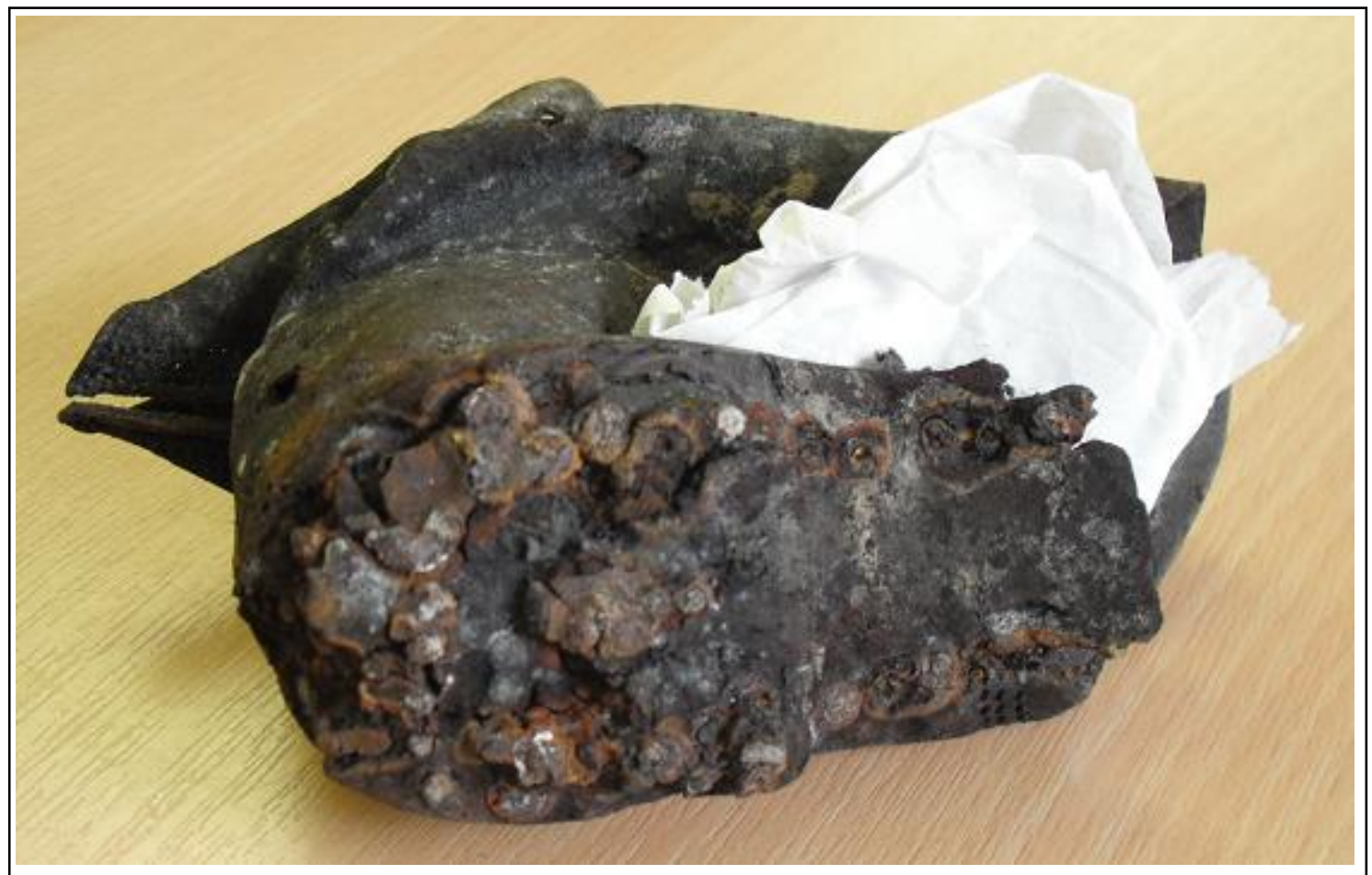

Figure 23 - Sole of OTLEY 2. (Photograph by C. Houlbrook) 


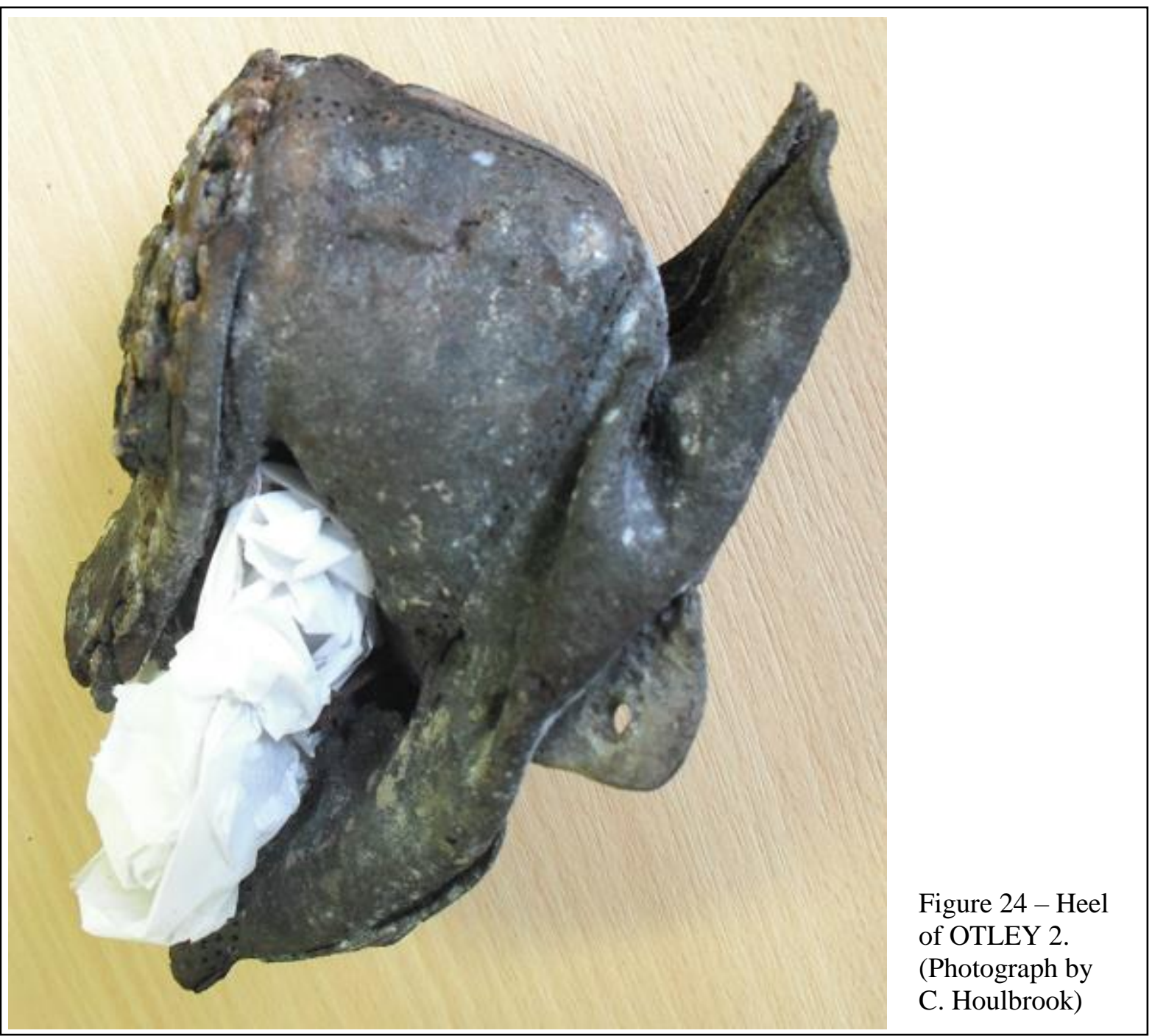

\section{Evidence of Ritualistic Behaviour?}

It has been observed by Brück that, in the realm of archaeology, an action which appears irrational or non-functional is often equated with ritual; 'ritual is identified by default' (2007: 284). Therefore, while it is certainly true that the concealment of old shoes appears, at first glance, both irrational and non-functional, it would be negligent to assume that the practice of concealment can be classified as ritualistic behaviour based on this one observation. However, before we can hope to consider whether or not the practice of concealment constitutes as ritual action, it is imperative that we clarify our criteria for ritualistic behaviour.

In the 1950s, anthropologist Nadel wrote that ritual is the 'formalism of action', action which exhibits a 'striking or incongruous rigidity' (1954: 99). For Firth, '[r]itual may be defined as a kind of patterned activity oriented towards control of human affairs, primarily symbolic in character' (1951: 222); for Goody, ritual refers to 'a category of standardized behaviour (custom) in which the 
relationship between the means and the end is not 'intrinsic', i.e. is either irrational or non-rational' (1961: 159); and for Schechner, ritual is defined as an efficacious performance (2002: 613). As we can see, definitions of ritual are multi-faceted and there are no 'watertight lists of criteria', to use Brück's term (2006: 283). However, if we are to put the concealed shoe into context, an effort must be made to propose our own definition. And so, for this essay, ritual is assumed to be a repetitive, habitual pattern of consciously and deliberately performed symbolic actions, employed for a specific function; usually to control, propitiate, protect from, or communicate with the supernatural.

With this definition in mind, it will now be our task to consider whether the practice of concealing shoes can indeed be classified as 'ritual'. That this practice was 'repetitive' and 'habitual' is certainly testified to by the sheer number of concealed shoes discovered, but a number of other questions must be considered if we are to conclude that the practice of concealment was indeed a ritualistic act, and if we hope to put the concealed shoe into context.

\section{Lack of Written Evidence}

As has been noted previously, there is an absence of contemporaneous literature on the subject of the concealed shoe. While this may simply be due to a lack of literacy on the part of the concealers, as Eastop (2007a: 66) and Hoggard (2004: 167) suggest, it seems unlikely that none of the concealers were literate, especially with $9.4 \%$ of concealed shoes having been discovered in manor houses and mansions (Swann 1996: 57). And as Merrifield rightly asks, why would the learned men of the nineteenth century have written so many works on other superstitious beliefs, and yet have ignored this practice, which was so obviously flourishing between the seventeenth and nineteenth centuries? (1987: 133) The answer is simple: the secrecy surrounding this practice was an integral, rather than incidental, part of the practice itself.

Swann, having failed to uncover any solid evidence for the motivations behind this practice, wrote that that she 'eventually realized that...the secrecy continually encountered suggest that the superstition, if disclosed, ceases to be effective' (1996: 67). The importance of secrecy is certainly in keeping with other rituals; Luhrmann, writing of modern-day wiccans, notes that magical practice 'requires secrecy in order to be effective', and that the 'reasoning behind this hinges on the partly unspoken assumption that power is a tangible emanation, somehow connected to oneself, which dissolves in the open, public air' (1989: 251). Lack of written evidence, therefore, may actually aid us in our classification of the concealed shoe as a ritual object; the practice of concealment was kept secret because it was a ritual that would lose its power once made public. 


\section{The Locations of the Shoes}

According to my definition, for the act of concealment to constitute ritualistic behaviour, each action must have been performed 'consciously and deliberately'. Although we cannot claim certainty, it seems highly unlikely that accidental losses can account for our case-studies, especially considering their locations. That OTLEY 1 and 2 would accidentally find themselves in the roof space with three other shoes, none of them paired, seems implausible, and that ILKLEY 1 could have been carefully placed on a narrow ledge within the chimney breast by pure chance seems even less likely. If they were concealed deliberately, however, then what was the purpose of their concealment?

The locations of the shoes provide us with a vital clue. OTLEY 1 and 2 were concealed within the roof space, while ILKLEY 1 was deposited in the chimney breast. These are both very common locations for concealed shoes, with $26.2 \%$ of recorded concealed shoes discovered in/near chimneys, hearths and ovens, $22.86 \%$ discovered under floors or above ceilings, with the roof space being the fourth most popular place for concealment (Eastop 2006: 246). One thing unites these different locations: their liminality.

The roof space of a building, with its peripheral location separating sky from house, represents marginality (Lloyd, et al, 2001: 69). The chimney also inhabits that indeterminable, transitional area between inside/outside; a grey area that is, according to Mary Douglas, dangerous; '[d]anger lies in transitional states,' she writes, 'simply because transition is neither one state nor the next, it is indefinable' (1966: 96). However, from the perspective of a person living in the eighteenth and nineteenth centuries, it was not necessarily the liminal nature of the roof space and the chimney that made them hazardous; there was a far more practical reason.

The outside world was rife with dangers, populated with malevolent forces that the home needed protection from (Reay 1985: 116). Scot, writing his Discoverie of Witchcraft in 1584, listed the plethora of forces to be feared: 'bull beggars, spirits, witches, urchens, elves, hags, fairies...' (Williamson 1964: 139). These were forces forever threatening to infiltrate the household from outside, and it was believed that the peripheral areas of the building provided access for them. As James I wrote in his Daemonologie of 1597, concerning popular beliefs of witches' familiars:

some of them sayeth, that being transformed in the likenesse of a little beast or foule, they will come and pearce through whatsoeuer house or Church, though all ordinarie passages be closed, by whatsoeuer open, the aire may enter in at (Harrison 1924: 39).

It was the marginal areas of a structure, therefore, such as the roof, that were considered the most vulnerable to these outside threats (Lloyd, et al, 2001: 57), and the chimney, providing the perfect access point for external forces, was viewed as particularly assailable. As Johnson writes, the witch, a liminal figure, was often accused of entering houses through similarly liminal areas, 
particularly the chimney (1996: 160-161). This explains why so many protective charms and objects of this period inhabited these marginal areas. Dried cats and horse skulls, common apotropaic devices, are often discovered in walls, chimneys or roofs, such as the horse skull found in a cavity beside a chimney in South Ockenden, Essex, and the mummified cat in the thatch of a cottage at Pilton, Northamptonshire (Merrifield 1987: 128-129).

Similarly, witch-bottles - bellarmine flasks containing the hair, nails and urine of a victim seeking to counter-attack a witch's spells (Thomas 1971: 544) - were often buried under thresholds or beneath the hearthstone of a house (Evans 1966: 78). We have also found numerous examples of inscriptions invoking the protective power of the Virgin Mary marked into doorways, roof beams, and fireplaces (Easton 1999), and it was for the same protective function that herbs, such as vervain and dill, were usually hung above the threshold (Thomas 1971: 543). These apotropaic devices were used to defend a household against magic, and yet, in a sense, they are objects of folk magic themselves. The irony of this did not go unnoticed at the time. As Richard Bovet observed in his Pandaemonium, 1684: men and women 'often became witches, by endeavouring to defend themselves against witchcraft' (Summers 1975: 53), and this fine line between magic and protection does seem to have caused anxiety, especially within the Church (Maxwell-Stuart 2005: 69ff). However, the sheer quantity of such apotropaic finds implies that, with or without approval from the Church, concealment was still a practice very widely accepted and utilised throughout England.

\section{The Symbol of the Shoe}

The protective devices discussed above may appear to have a more obvious preternatural function than the seemingly innocuous object of the shoe, but given the comparability of their concealed locations, it seems fair to assume that the shoe served a similarly efficacious and apotropaic purpose and, as the most commonly discovered concealed object in England (Hoggard 2004: 178), the shoe must have embodied a significant amount of symbolism. It is therefore our aim now to investigate the beliefs behind this symbolism.

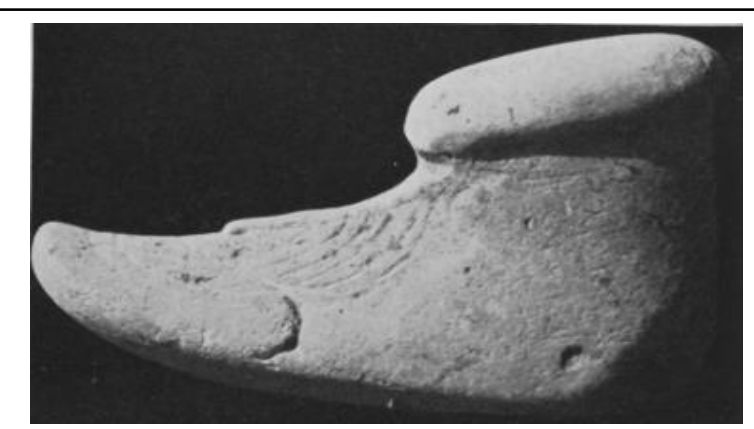

Figure 25 - Model votive shoe, Tell-Brak. (From Mallowan 1947: Plate VII)
The shoe has been an object of ritual significance since as early as the $34^{\text {th }}-32^{\text {nd }}$ centuries BC, when a limestone votive shoe (fig. 25) was placed in the 'Eye-Temple' of Tell-Brak, modern-day Syria. From this time onwards, we find the shoe cropping up as a ritual object, time and time again, in a vast range of cultures, and Murray credits this to 


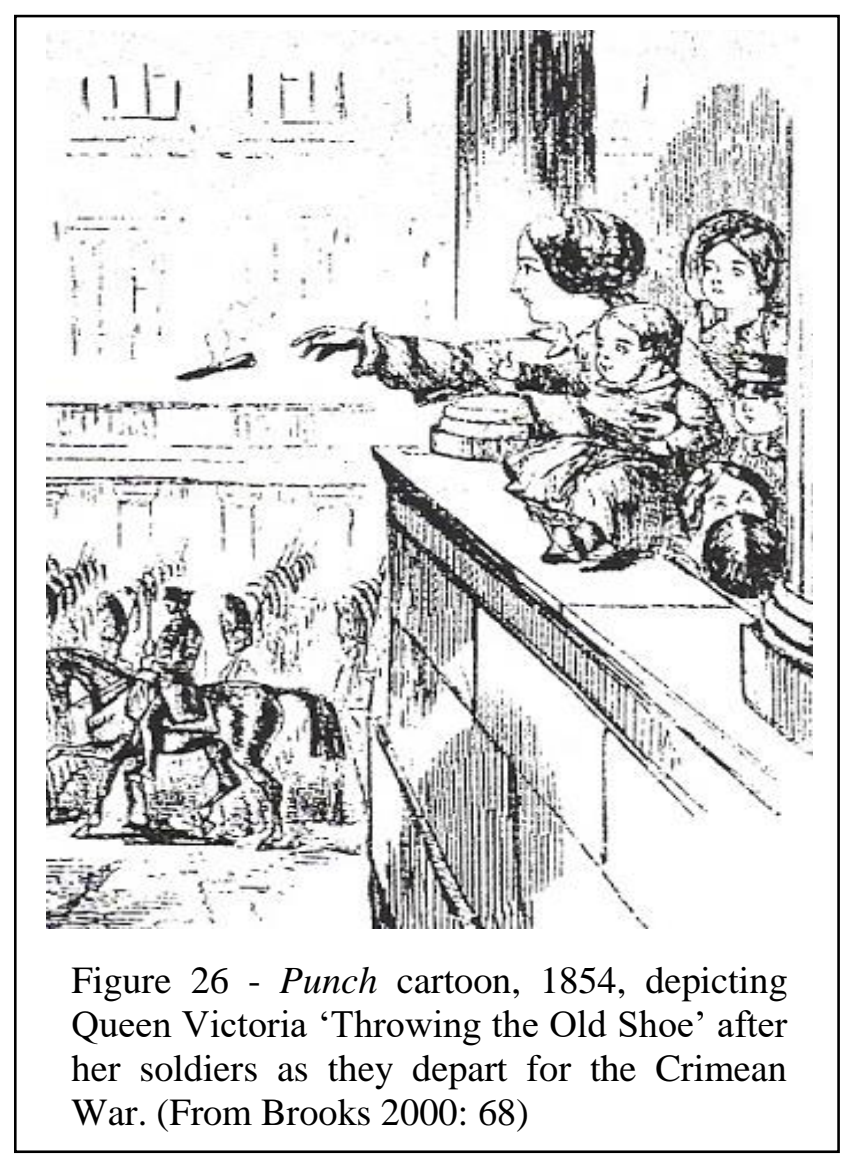

the foot being 'a liminal extremity, on the cusp between us and the soil...Feet are on the frontier and it is around frontiers that rituals accumulate' (1999: 131). And so it is the liminality of the shoe itself that resulted in its prominence in worldwide superstitious beliefs, such as its intrinsic association with luck. As Radford and Radford write, it is considered unlucky to put your left shoe on first (1948: 158), to find a knot in your shoe lace (1948: 306), and to place a new shoe on a table (1948: 305). It is, on the other hand, considered good luck to throw an old shoe after somebody as they begin a journey (fig. 26); as John Heywood wrote in 1598: 'And home agayne hytherward quicke as a bee, Now for good lucke caste an olde shoe after mee' (Milligan 1956: 1.9.37-38).

The shoe is also associated with concepts of fertility; if a woman places a shoe on a table it foretells the birth of a child (Radford and Radford 1948: 305); in Lancashire, if you try on the shoes of a woman who has recently given birth then you too will soon conceive (Merrifield 1987: 134); and the practice of throwing shoes at a wedding may stem from some notion of deterring demons who might cause barrenness (MacCulloch 1920: 476). The shoe's association with fertility may explain why so many concealed shoes, such as ILKLEY 1 and OTLEY 1, belonged to children, and why, of the concealed objects in Otley Museum's records, 65\% of them were children's. Perhaps the concealed shoe was designed to ensure fertility, or perhaps it was meant to protect the children of the household; a north German superstition, for example, maintains that so long as the child's first shoe is kept in the house, the child will come to no harm (Murray 1999: 136).

The shoe's primary purpose does seem to have been protection. This can indicate protection against illness; in the northern counties of England, for example, laying shoes across each other would prevent cramps, rheumatism and nightmares (Henderson 1879: 1550). However, the shoe's main protective function, cross-culturally, appears to be against malevolent supernatural forces. In India, the shoe is placed heel upwards on the roof of a house to ensure such protection (MacCulloch 1920: 476), and in order to defend their crops against evil forces, they are advised to ' $[\mathrm{t}] \mathrm{ie} . .$. an old shoe on a choice fruit tree or vine' (Maloney 1976: 116). African-American folk-beliefs prescribe burying a 
shoe under the full moon to keep the devil away (McCarthy 2001: 43), and they also advise wearing red-pepper in your shoes to protect against hoodoo spells (Puckett 1926: 289).

It can hardly be doubted that the shoe is considered a symbol of protection, but the question remains: why? One theory is that, in popular belief, evil spirits did not like the smell of burning leather. In Britain, fairies were believed to be repelled by strong odours, such as garlic or the burning of an old shoe (MacCulloch 1914: 202), and as Radford and Radford write, it was a widely held belief in early England that '[t]he smell of burning shoes keeps off demons and serpents' (1948: 306). This theory would certainly fit with our case-studies; all of the shoes at both Ilkley and Otley were made primarily from leather, and it may explain why so many concealed shoes, such as ILKLEY 1, were deposited in/near chimneys, fireplaces and hearths; they were originally meant to be burnt.

Another theory regarding the protective function of the shoe is put forward by Merrifield. He

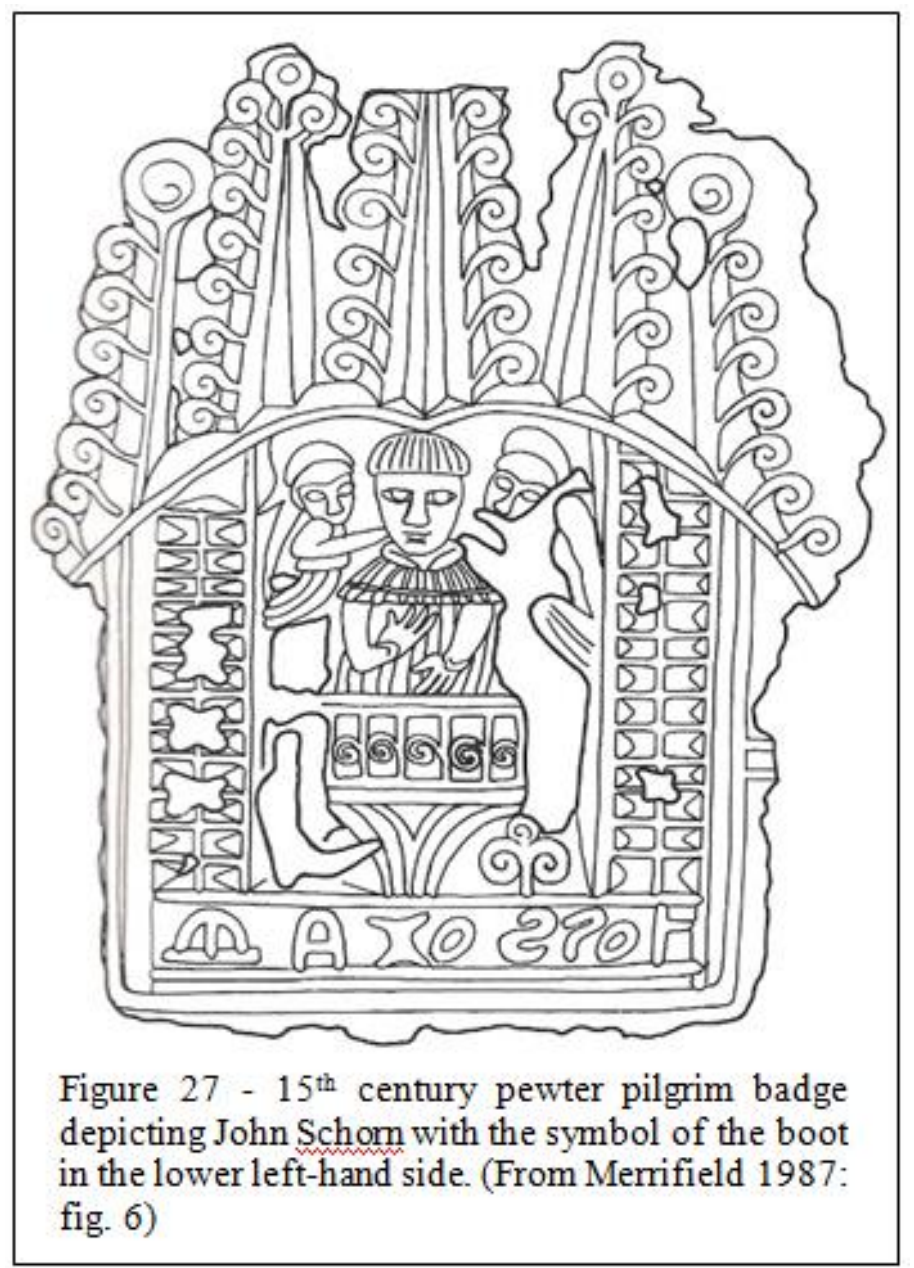
hypothesises that the tradition stems from the tale of John Schorn, a parish priest from Buckinghamshire and one of England's unofficial saints, who was believed to have conjured a devil into a boot (fig. 27) (1987: 135). The shoe, therefore, became a type of 'spirit trap' in popular belief (Hoggard 2004: 179), and this may be due to its bowl-like shape which can act as a type of container (Brooks 200: 68). However, the shoe is also believed to act as a 'lightening conductor', to use Easton's phrase, in diverting the supernatural force from entering the house (1999: 23); the evil spirit 'sees' the shoe and, believing it to be a member of the household, attacks the shoe instead, thus becoming trapped. But why would the spirit perceive the shoe as a member of the household? 


\section{The Shoe and the Wearer}

Shoes are highly personal items. Murray believes that '[a]s bearer of the individual's imprint, the shoe functions as a signature - a spiritual graffito' (1999: 136); even in ancient Rome, the soles of shoes were personalised with what Murray considers to be 'good luck symbols', such as circles, s-shapes, and tridents, fixed into the sole by the pattern of the hobnails (fig. 28), which would, in turn, leave the wearer's symbol, their 'signature', in the earth as they walked. A shoe, therefore, is intrinsically linked with its wearer, and that the concealed shoe represents a member of the household is a theory originally put forward by Swann. 'Why the shoe?' she asks; because it is 'the only garment we wear which retains the shape, the personality, the essence of the wearer' (1996: 56). By retaining the foot's shape, the shoe becomes a metaphorical symbol of the wearer, imbued with their essence. This metonymical link with the wearer, however, makes the shoe more than just a diversion or a lure; it is a protective force in itself, endowed with the person's power.

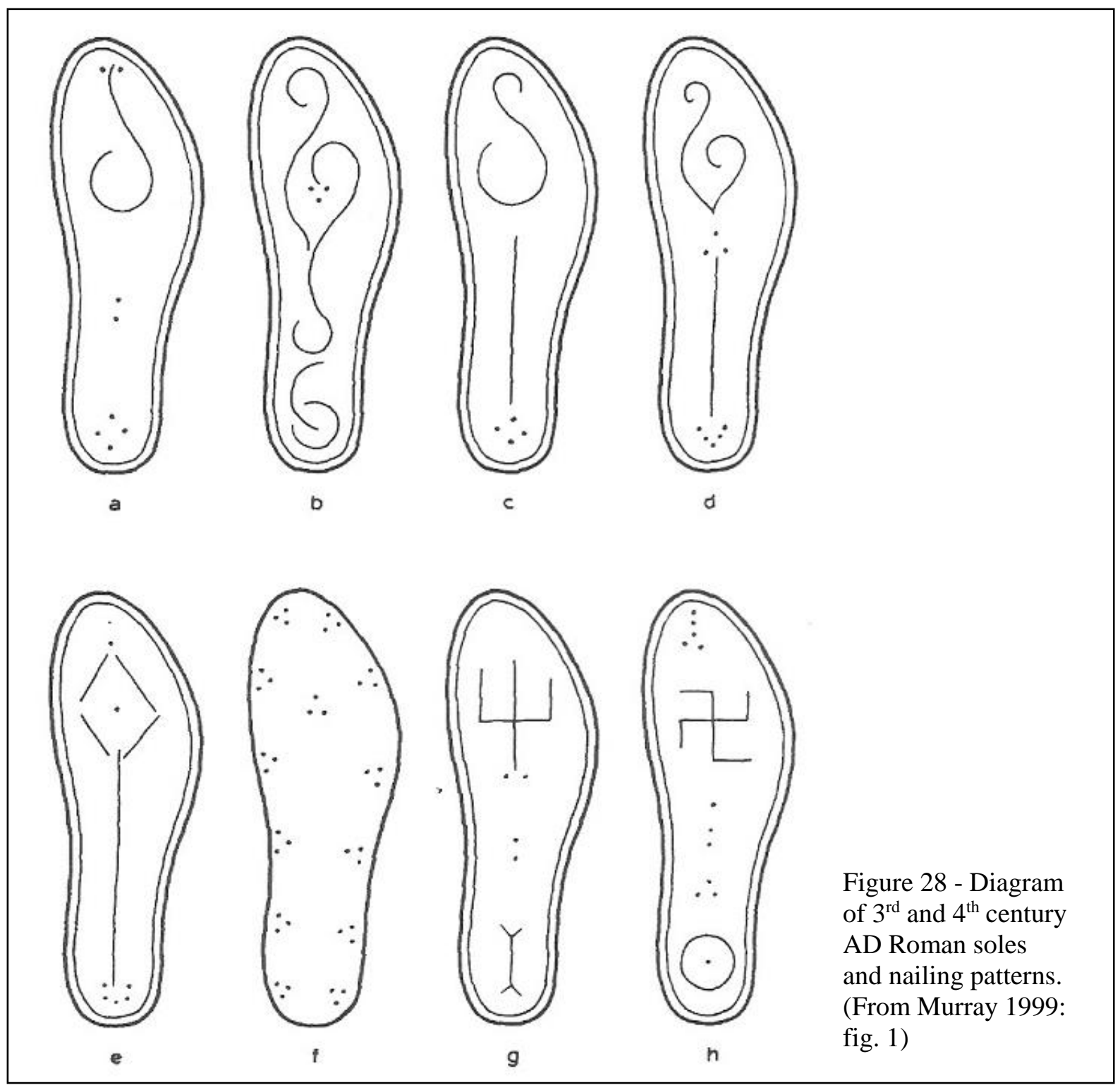


Other items of clothing are imbued with a similar power, and nowhere do we see this more clearly than in the fairytale told by Hartland: when fairies came to steal a newborn baby near Selkirk, the mother covered herself and the child with her absent husband's waistcoat; the fairies subsequently left, causing no harm. As Hartland writes, the 'suggestion seems to be that the sight of the father's clothes leads "the good people" to think that he himself is present watching over his offspring' (1891: 98). The same could indeed be true of shoes, and this may explain why so few - a mere $2.19 \%$ of those recorded in the Concealed Shoes Index in Northampton (Swann 1996: 59) - appear to be new, while the remaining $97.81 \%$ were old and damaged, much like the shoes of our case-studies (figs. 2933). ILKLEY 1 has a seemingly unservicable hole in the toe, OTLEY 1 was in poor condition before restoration, and OTLEY 2 is so badly damaged that it is barely recognisable as footwear. Perhaps shoes are only imbued with the wearer's essence and protective power if they have been worn by them for a long time and their imprint is thus unambiguous (Murray 1999: 137).

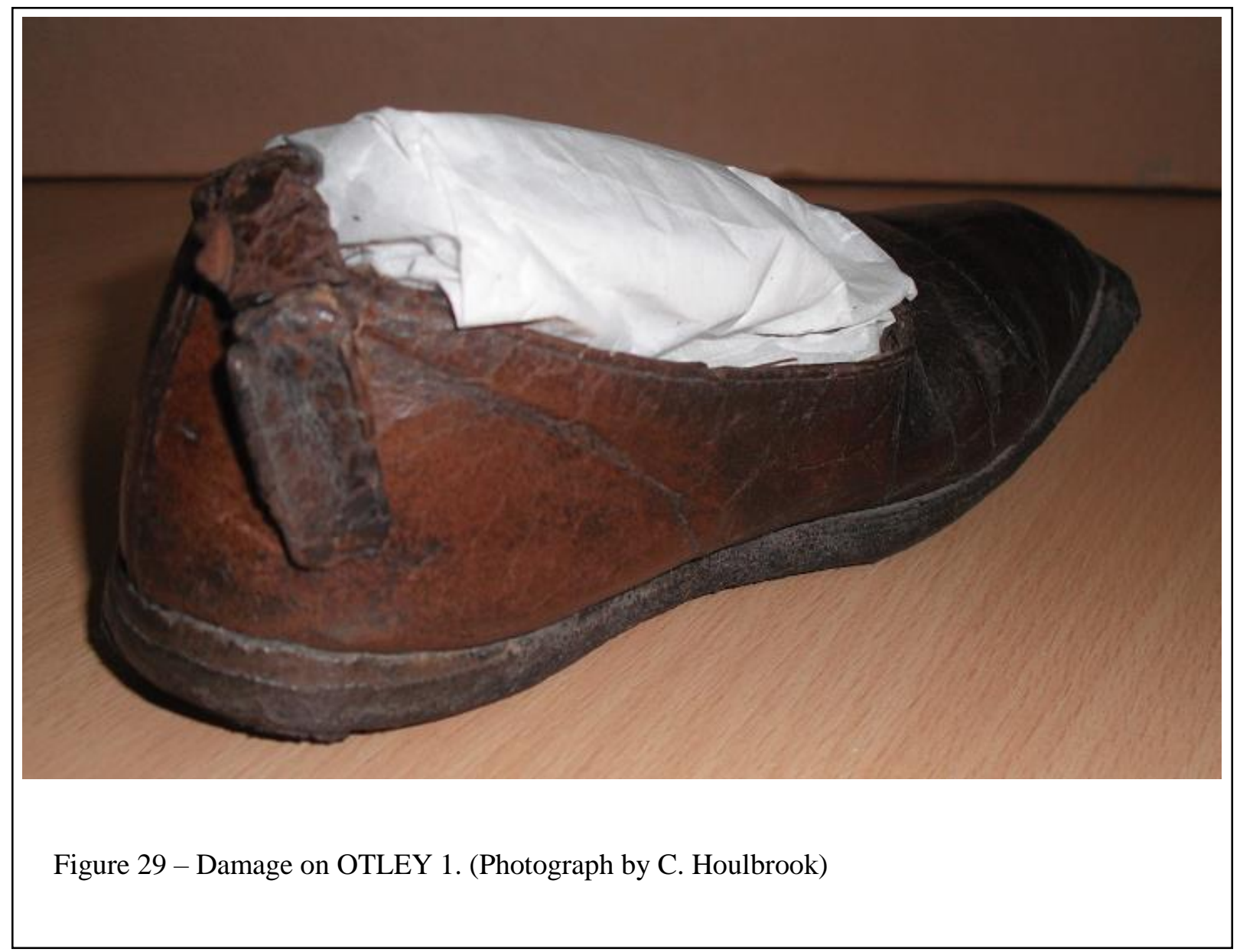


Ceri Houlbrook

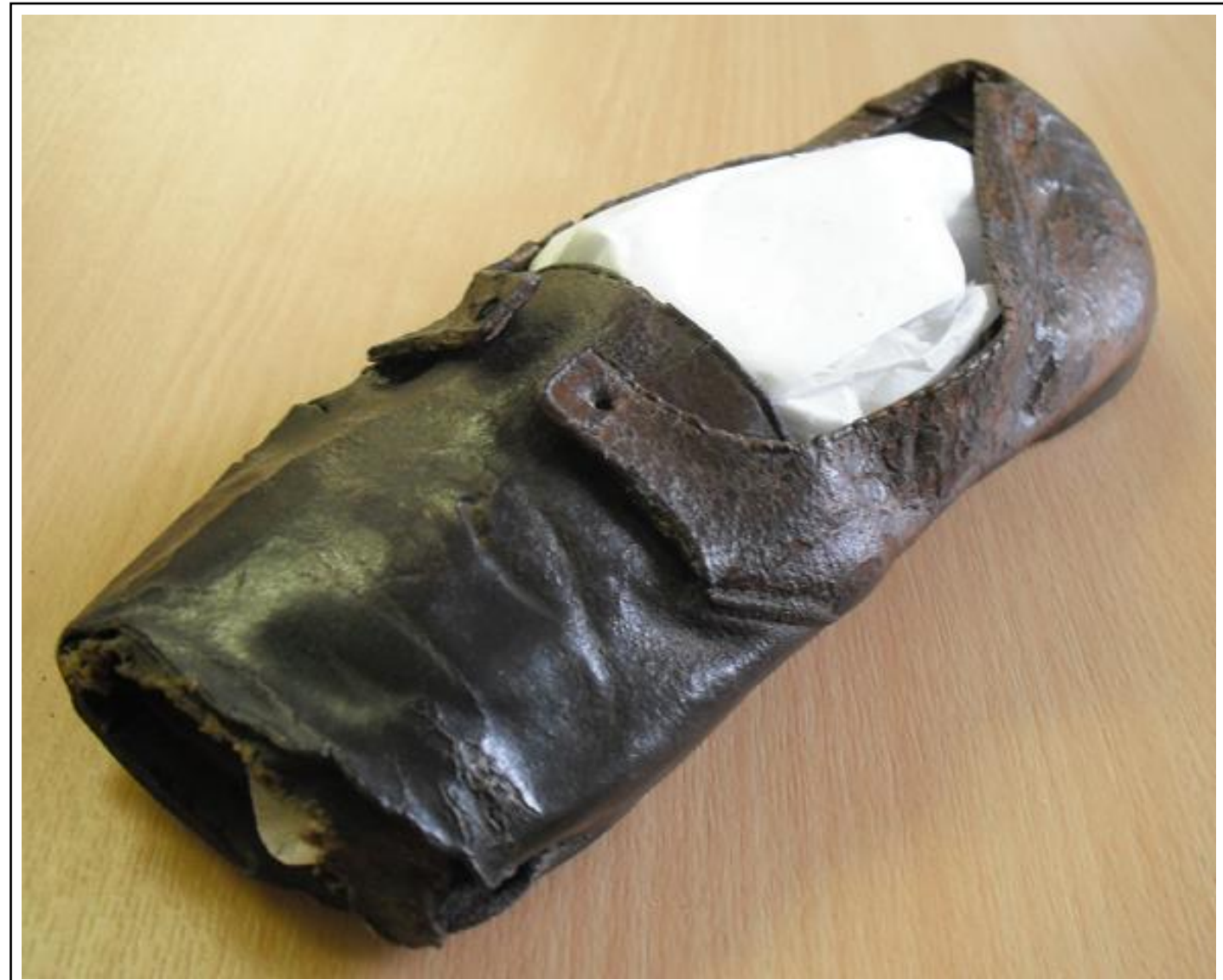

Figure 30 - Damaged toe of O/MP/ft/4, man's shoe, Otley. (Photograph by $\mathrm{C}$. Houlbrook)

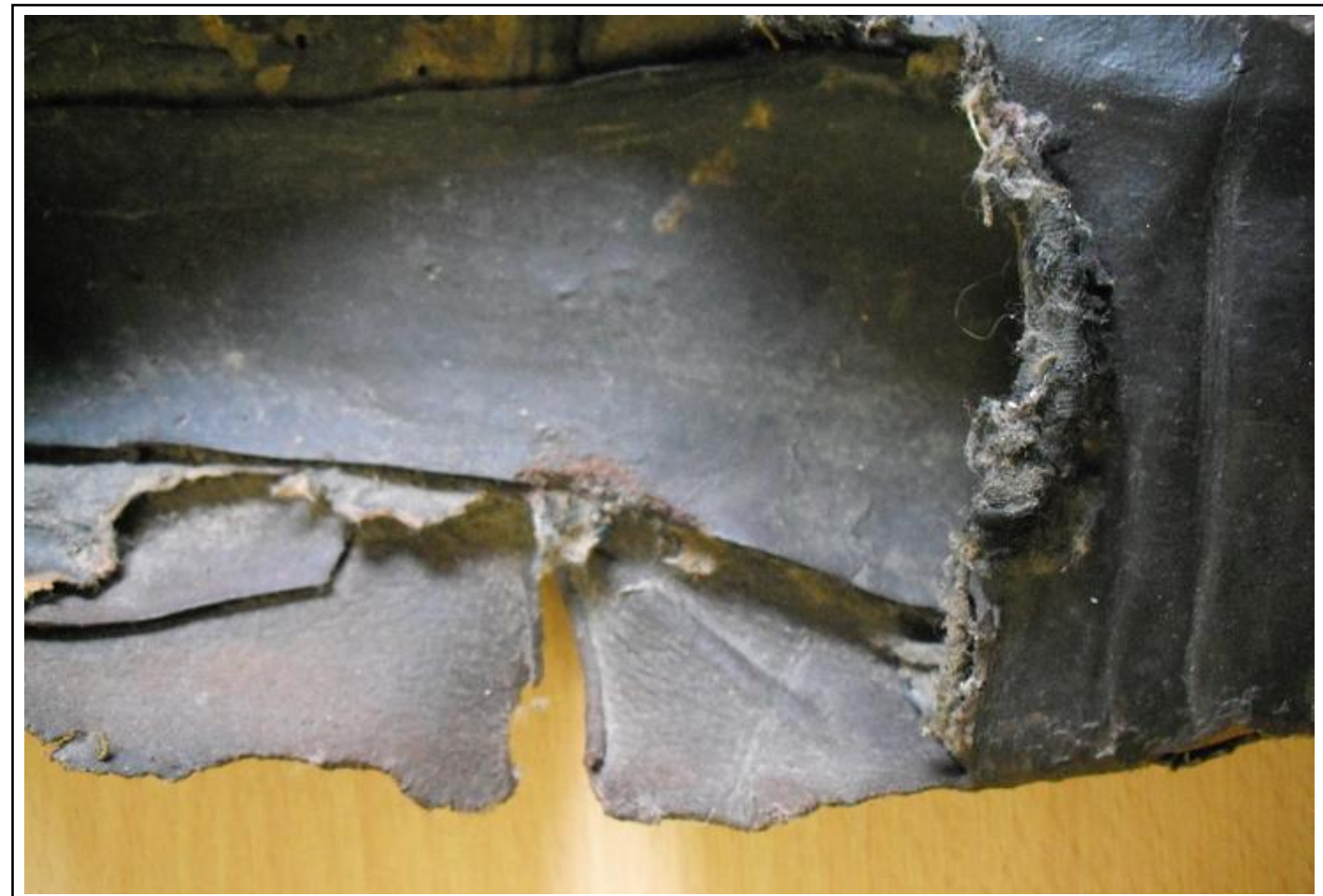

Figure 31 - Damage of adult's shoe found in Lane End Farmhouse, Ilkley. (Photograph by C. Houlbrook) 

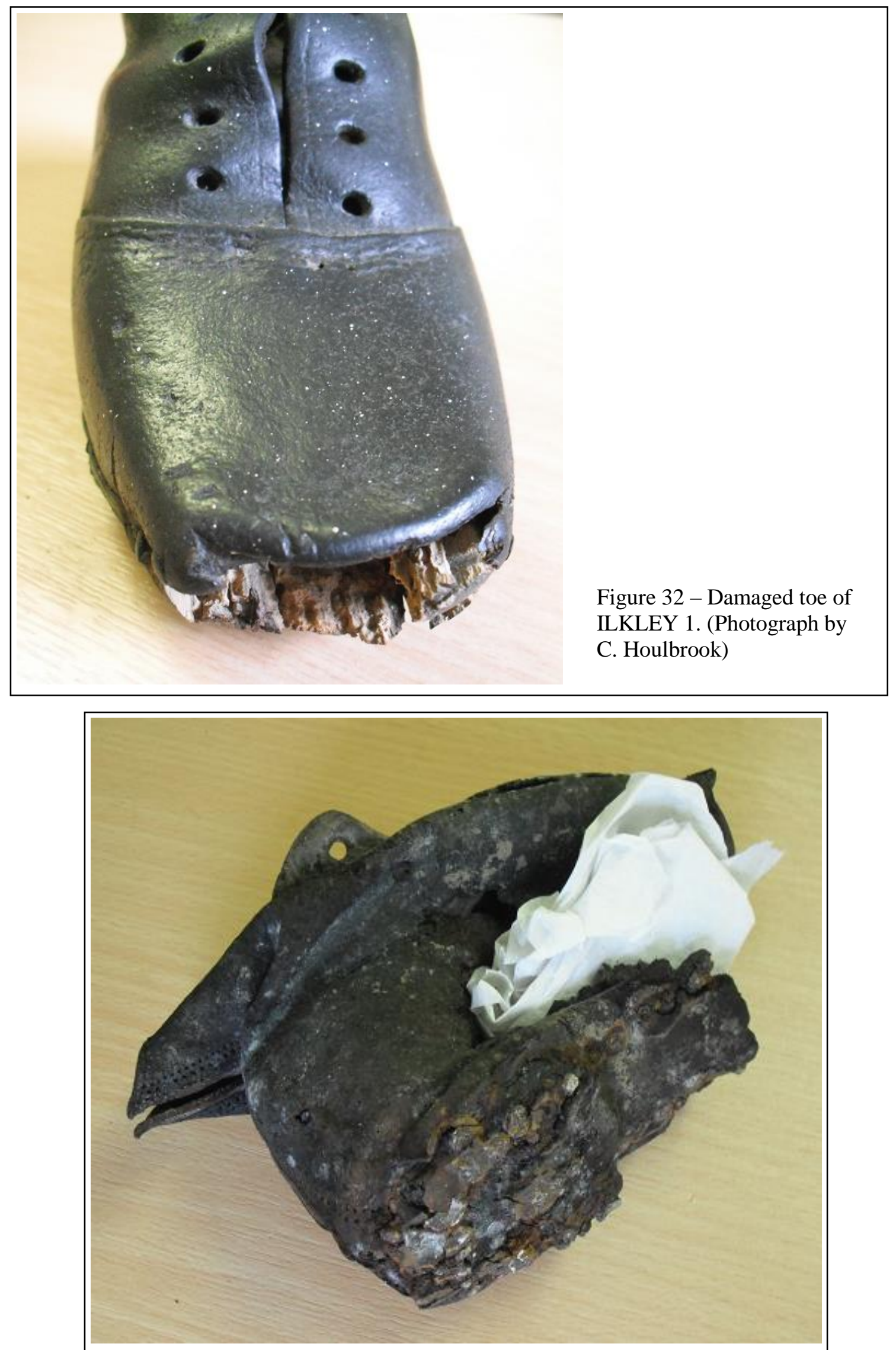

Figure 33 - Damaged condition of OTLEY 2. (Photograph by C. Houlbrook) 
However, there is a simpler explanation for the old and damaged conditions of the concealed shoes. Shoes were expensive items; on average, a pair of shoes cost a week's wages (Swann 1996: 59). These were not items casually thrown away, but will have been repaired, modified, and altered until they were no longer servicable; then, and only then, would they have been discarded - or recycled as a concealed shoe. Perhaps this too explains the prominence of children's shoes; children's shoes were used so often because children outgrow their footwear much more regularly than adults do. A child's shoe will quickly become redundant; dispensible enough to be utilised in ritual. However, I do not believe that old shoes were used in such a way only because they had lost their value as footwear, but also because they had gained value, as old and well-used, by being imbued with their wearer's essence. It was, in my opinion, for both reasons simultaneously that the old and damaged shoe shoe was recycled as a ritual object.

And at this stage I believe there is very little doubt that the concealed shoe can be considered a ritual object. While there may be much ambiguity over the original meaning of the practice, the essential critera of ritual - as outlined in my definition above: 'a repetitive, habitual pattern of consciously and deliberately performed symbolic actions, employed for a specific function; usually to control, propitiate, protect from, or communicate with the supernatural' - are certainly evident in the practice of concealment. There is indeed a repetitive, habitual pattern of consciously and deliberately concealing shoes, which are indubitably symbolic objects, for the probable, efficacious purpose of protection against supernatural forces. The concealed shoe, therefore, can be classified as a ritual object.

\section{The Redundancy of Dichotomies}

The concealed shoe may be classifiable as a ritual object, but any other labels we may hope to apply to it remain precarious. As archaeologists, we are accustomed to classifying an object as either 'sacred' or 'secular', 'numinous' or 'profane', and we are often quick to judge which category an object falls under. On studying the concealed shoe, however, it soon becomes clear that such stringent terms are not always accurate, and they are certainly not always mutually exclusive. The dichotomy between 'sacred' and 'secular' may seem pertinent to us, but would the original concealers of the shoes in Ilkley and Otley have distinguished between the two? As Goody observes, 'attempts to see...the sacred-profane dichotomy as a universal part of the actor's perception of his situation are misleading' (1961: 160); for the actor - or concealer - no such dichotomy may have existed. Or, as Insoll points out by reminding us that '[r]itual...can be both sacred and secular' (2004: 10), it is not necessarily a case of either/or; an object may be simultaneously numinous and profane. 
We see this clearly in Mackenzie's interpretive study of the looped string bag (bilum) of the Telefol people of central New Guinea, in which she examines 'the ways in which the string bag is variously used and understood within differing social contexts' (1991: 1). The string bag is utilised as a practical tool, as a container or baby carrier; simultaneously, it also acts as a spirit catcher, a shrine, a fertility aid, and a weapon to protect against supernatural forces (1991: 11). Mackenzie discovered as she studied the bilum that no object exists in isolation; no object is static or fixed, but is instead adapted and re-interpreted as it shifts from one context to another. In this sense, the concealed shoe and the bilum are much alike; through the process of ritual recycling, the shoe's purpose is revised. ILKLEY 1 and OTLEY 1 and 2 were not originally created as apotropaic devices, but to serve the decidedly profane purpose of physically protecting the foot. Only when they could no longer serve this function were they then imbued with the power to protect against supernatural forces. Apotropaic powers are not inherent to an object; an object is appointed that power, given that agency by the users/concealers themselves.

This theory of attributed agency was put forward by anthropologist Gell (1998), who writes in detail of the protective agency of objects of art which are imbued with the power to protect their agents. Once we attribute the concealed shoe with Gell's concept of 'agency', however, we are also forced to consider the object/subject dichotomy. Up until this point, we have been labelling the concealed shoe an 'object', but it has been proposed by scholars such as Kopytoff (1986) that when something is given such agency, it becomes a 'subject' instead. An object, it is believed, can have no agency. And so, according to this theory, the concealed shoe is viewed as an active, almost anthropomorphised subject rather than an inert, passive object; it does, rather than has things done to it. However, 'object' and 'subject' are not fixed states; the concealed shoe fluctuates between the two. It is only when the shoe is imbued with protective power does it become a 'subject'. Before this, when it was used only as an item of footwear, the shoe was still a simple 'object'; it had neither power nor agency. Therefore, the concealed shoe can be perceived as both an 'object' and a 'subject', depending on its context.

A similar dichotomy which the concealed shoe calls into question is that of 'value' and 'rubbish'. Is the concealed shoe a valuable object or an item of rubbish? Simply put, the answer depends on the individual perspective of the viewer. As Mackenzie writes, 'value is not inherent...but multivalent and variously realised' (1991: 21). Today, such discovered shoes have no actual material, monetary value. To some finders, the concealed shoe may just be a dirty, cobweb-covered scrap of twisted leather found in the dark recesses of their attic, fit for nothing but the rubbish bin. To other people (myself included), such a shoe is a prized archaeological find. And to the original concealers themselves, a similar ambiguity may have been evident in their perceptions of the concealed shoe. Why were they chosen for concealment in the first place? Because they were old, damaged and no longer fit to be worn. They were rubbish. But they were valued rubbish (Easton 1999: 23); they were 
items of refuse selected for ritual recycling, through the process of which they attained new worth as numinous, apotropaic devices. They transition from 'valuable' to 'rubbish', and return to 'valuable' once more, revealing that these states of value are fluid, highly malleable and completely subjective (Thompson 1979: 10).

\section{The Biography of the Shoe}

The processual notion of the 'biography' of an object goes back to Kopytoff, who believes that an object's life-cycle should be viewed similarly to that of a human's: as a series of 'ages' from 'birth' to 'death' (1986: 66-67). An object's biography, however, can prove far more complex and convoluted than that of a human's. The shoes of Ilkley and Otley, for example, are not static, immutable objects; their life-spans are far from linear, frequently shifting from one context to another, and then reverting back again. They reach the 'death' of one stage, and are 'reborn' in another.

During its life-span, the concealed shoe undergoes a wealth of such 'recontextualisation' (Thomas 1991: 8), as an object that is constantly being adapted, reutilised, and redefined. However, it is important to remind ourselves that these processes of adaptation, reutilisation and redefinition are human activities (Steiner 2001: 211); the concealed shoe does not recontextualise itself. Henceforth, the biographies of the Ilkley and Otley shoes are intrinsically linked with the people they come into contact with: their wearers, their concealers, and their finders (Gosden and Marshall 1999: 169; Hoskins 2006: 81).

We have already discussed the concealed shoe as a ritually recycled object; when they could no longer serve their original utilitarian purpose, they were appropriated as apotropaic devices. This, however, is certainly not the only transition the concealed shoe undergoes. Following re-discovery, a concealed shoe is recontextualised yet again, taking one of three paths. It can be disposed of as rubbish, such as the shoe discovered at Market Street, Otley, which was discarded before Christine Dean rescued the remaining five. Many such finds, in fact, are regarded as rubbish and subsequently discarded, its 'biography' sadly ending in the rubbish tip (Eastop 2007a: 66). Fortunately, however, there are two other paths a concealed shoe can take following discovery: it can either be retained by the finder and kept in situ, or donated to a museum.

ILKLEY 1 was retained by its finder, and when she moved from the farmhouse, she left the shoe in situ. Two years later, the new resident of the farmhouse, Kate Armitage, placed ILKLEY 1 on a shelf above the fireplace in which it was originally concealed (fig. 34). When questioned about the choice of location, Kate Armitage explained that she wished the shoe to be kept as close as possible to its original place of concealment; it was hidden there for a reason, she believes, and as unfathomable 
as that reason may be to her, she does not want it to be removed. Like the previous owner of the house, Ms. Armitage also maintains that if she ever moved from the farmhouse, she would not take the shoe with her; it is a part of the house. ${ }^{3}$

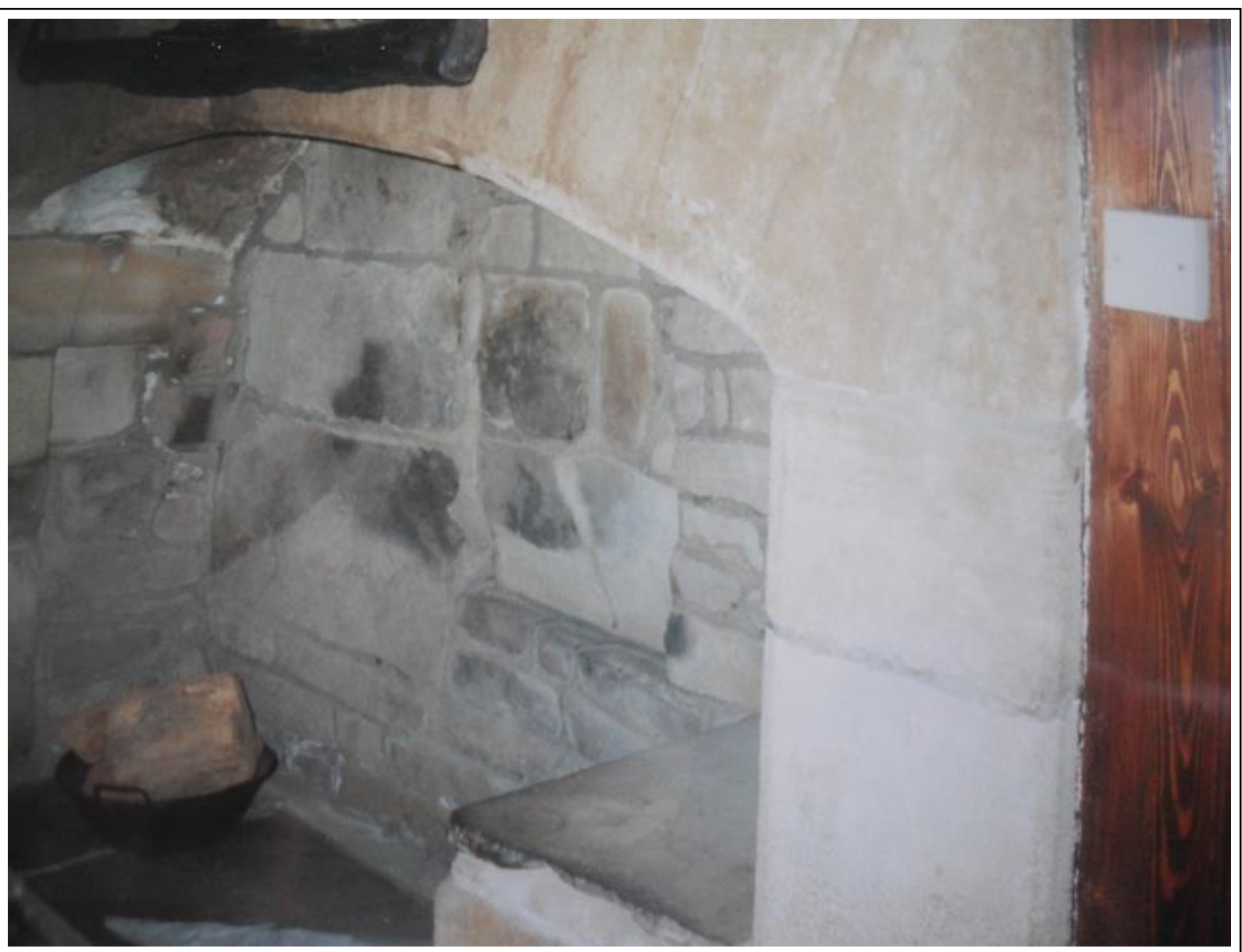

Figure 34 - The fireplace in which ILKLEY 1 was discovered. It is stored on the shelf above. (Photograph by Kate Armitage)

It is not unusual for a concealed shoe to be retained by its finder. In fact, out of the 31 concealed garments in the Otley Museum records, 17 were returned to their finders, and there seems to be a widespread belief that removing a concealed shoe will result in bad luck. When a cache of boots and shoes were found in Colby Estate in Pembrokeshire, for example, the farmer's wife demanded that they be boarded up again immediately (Brooks 2000: 68) and Swann recounts the experiences of another finder who 'reported that while the boots were out of the house for exhibition, they had nothing but bad luck, the death of pets, flooding and the shed fell down. They now wished to leave the boots strictly alone, no publicity, no photography' (Swann 1996: 65). Finders thus become concealers themselves (Eastop 2006: 250), and ILKLEY 1 retains its value as a concealed shoe.

\footnotetext{
${ }^{3}$ Personal correspondence with Kate Armitage
} 
OTLEY 1 and 2, on the other hand, were removed from their places of concealment, donated to Otley Museum, and thus entered 'another social sphere' (Eastop 2007b: 201). These shoes therefore transition from concealed objects to displayed objects; they have been removed from situ and are therefore no longer valued for their apotropaic powers. OTLEY 1 especially can be perceived as having lost any of the agency it was once imbued with; unlike OTLEY 2, which has retained its old and damaged appearance, OTLEY 1 was restored and is therefore now lacking in the 'essence' of its wearer. Instead, it is now valued as a historical artefact, to be studied by textile conservationists and folklore archaeologists. Once more, this shoe has been re-appropriated and recontextualised; from footwear, to apotropaic device, to archaeological evidence. It has entered yet another of the multitude of stages that the concealed shoe passes through during its life-span. And I doubt it will be the last.

\section{Conclusion}

Although we walk away with no definite answers about the concealed shoe - for it can never be stated with any certainty why the original concealers of the Ilkley and Otley shoes chose to hide these objects in their homes - we are, I believe, much closer to understanding the motivations behind this mysterious practice. We have concluded, based on my proposed definition of 'ritual', that the act of concealment does indeed constitute ritual behaviour, and that the shoe, as a powerful symbol with a plethora of folkloric associations, was utilised as an apotropaic device to protect against the myriad of malevolent forces that the average eighteenth and nineteenth-century household felt threatened by. The enigma of the concealed shoe thus comes a step closer to being solved, and - in the analysis of the objects themselves - we gain a greater insight into the beliefs of these people.

It was also my promise, given the title of this essay, to put the concealed shoe into context. This, however, has proved impossible. The concealed shoe is an object (or subject) that is so mutable, so frequently fluctuating, that one single context will not suffice. It shifts from context to context, from location to location, ranging from the storage box in a museum, to the dark, dangerously peripheral areas of an eighteenth-century farmhouse. And just as the shoe is located in liminal areas of a building, so too does it stand in liminal areas of archaeological theory, as an object of ambiguity that defies classification; both profane and numinous, a ritual item and a secular item, valuable and rubbish. And therefore so long as we are determined to categorise and stringently classify all findings, we remain ill-equipped to understand the complexities and malleability of an object such as the concealed shoe.

Ceri Houlbrook, Department of Archaeology, The University of Manchester ceri.houlbrook@postgrad.manchester.ac.uk 


\section{Bibliography}

- Appadurai, A. (ed.) 1986. The Social Life of Things: Commodities in cultural perspective. Cambridge, Cambridge University Press.

- Attfield, J. 2000. Wild Things: The Material Culture of Everyday Life, Oxford and New York, Berg.

- Bovet, R. 1684. Pandaemonium. In Summers, M. 1975. Wakefield, EP Publishing.

- Bradley, R. 1997. Death by Water: Boats and Footprints in the Rock Art of Western Sweden. Oxford Journal of Archaeology 16 (3), 315-324.

- Brooks, E. 2000. Watch your Step. National Trust Magazine 91, 67-68.

- Brück, J. 2006. Ritual and rationality: Some problems of interpretation in European archaeology. In Insoll, T. (ed.) The Archaeology of Identities: A Reader. New York, Routledge: 281-307.

- Douglas, M. 1966. Purity and Danger: An analysis of concepts of pollution and taboo. London, Routledge \& Kegan Paul.

- Easton, T. 1997. Spiritual Middens. In Oliver, P. (ed.) Encyclopedia of Vernacular Architecture of the World 1. Cambridge, Cambridge University Press: 568.

- Easton, T. 1999. Ritual Marks on Historic Timber. Weald and Downland Open Air Museum Magazine, 22-30.

- Eastop, D. 2001. Garments deliberately concealed in buildings. In Wallis, R. J. and Lymer, K. (eds.) A Permeability of Boundaries? New Approaches to the Archaeology of Art, Religion and Folklore. Oxford, J. \& E. Hedges: 79-83.

- Eastop, D. 2006. Outside In: Making Sense of the Deliberate Concealment of Garments within Buildings. Textile 4 (3), 238-255.

- Eastop, D. 2006. Conservation as Material Culture. In Tilley, C. Keane, W. Küchler, S. Rowlands, M. and Spyer, P. (eds.) Handbook of Material Culture. London, Sage: 516-533.

- Eastop, D. 2007a. Sound recording and text creation: oral history and the Deliberately Concealed Garments Project. In Hayward, M. and Kramer, E. (eds.) Textiles and Text: Reestablishing the Links Between Archival and Object-Based Research. AHRC Research Centre for Textile Conservation and Textile Studies Third Annual Conference. London, Archetype Publicaitons: 65-70.

- Eastop, D. 2007b. Material culture in action: conserving garments deliberately concealed within buildings. Anais do Museu Paulista: História e Cultura Material, 15 (1), 187-204.

- Ewart Evans, G. 1966. The Pattern under the Plough: Aspects of the Folk-Life of East Anglia. London, Faber and Faber.

- Firth, R. 1951. Elements of Social Organization: Josiah Mason Lectures delivered at the University of Birmingham. London, Tavistock Publications. 
- Gell, A. 1998. Art and Agency: An Anthropological Theory. Oxford, Clarendon.

- Goody, J. 1961. Religion and Ritual: The Definitional Problem. British Journal of Sociology $12,142-164$.

- Gosden, C. and Marshall, Y. 1999. The Cultural Biography of Objects. World Archaeology $31(2), 169-178$.

- Harding, J. S. 1934. The Boot and Shoe Industry. London, Sir Isaac Pitman \& Sons Ltd.

- Hartland, E. S. 1891. The Science of Fairy Tales: An inquiry into fairy mythology. London, Kessinger Publishing.

- Henderson, W. 1879. Notes on the Folk-Lore of the Northern Counties of England and the Borders. London, Satchell, Peyton.

- Heywood, J. 1598. Works. In Milligan, B. A. (ed.) 1956. John Heywood's Works and Miscellaneous Short Poems. Urbana, University of Illinois Press.

- Hoggard, B. 2004. The archaeology of counter-witchcraft and popular magic. In Davies, O. and de Blécourt, W. (eds.) Beyond the witch trials: witchcraft and magic in Enlightenment Europe. Manchester, Manchester University Press.

- Hoskins, J. 2006. Agency, Biography and Objects. In Tilley, C. Keane, W. Küchler, S. Rowlands, M. and Spyer, P. (eds.) Handbook of Material Culture. London, Sage: 74-84.

- Insoll, T. 2004. Archaeology, Ritual, Religion. London, Routledge.

- James I. 1597. Daemonologie. In Harrison, G. B. (ed.) 1924. London, John Lane.

- Johnson, M. 1996. An Archaeology of Capitalism. Oxford, Blackwell.

- Kalm, P. 1748. Kalm's Account of His Visit to England on His Way to America in 1748. In Lucas, J. (ed.) 1892. London and New York, MacMillan and Co.

- Kopytoff, I. 1986. The cultural biography of things: commoditization as process. In Appadurai, A. (ed.) The Social Life of Things: Commodities in cultural perspective. Cambridge, Cambridge University Press: 65-91.

- Latour, B. 2004. Why Has Critique Run out of Steam? From Matters of Fact to Matters of Concern. Critical Inquiry 30 (2), 225-248.

- Lloyd, V. Dean, J. and Westwood, J. 2001. Burn marks as evidence of apotropaic practices in houses, farm buildings and churches in Post-Medieval East Anglia. In Wallis, R. J. and Lymer, K. (eds.) A Permeability of Boundaries? New Approaches to the Archaeology of Art, Religion and Folklore. Oxford, J. \& E. Hedges: 57-70.

- Luhrmann, T. M. 1989. Persuasions of the Witch's Craft: Ritual Magic and Witchcraft in Present-day England. Oxford, Blackwell.

- MacCulloch, J. A. 1910. Changelings. In Hastings, J. Gray, L. H. And Selbie, J. A. Encyclopaedia of Religion and Ethics 3. Edinburgh, T. \& T. Clark: 358-363. 
- MacCulloch, J. A. 1914. Incense. In Hastings, J. Gray, L. H. And Selbie, J. A. Encyclopaedia of Religion and Ethics 7. Edinburgh, T. \& T. Clark: 201-205

- MacCulloch, J. A. 1920. Shoes and Sandals. In Hastings, J. Gray, L. H. And Selbie, J. A. Encyclopaedia of Religion and Ethics 3. Edinburgh, T. \& T. Clark: 476.

- Mackenzie, M. A. 1991. Androgynous Objects: String bags and gender in central New Guinea. Chur and Reading, Harwood Academic Publishers.

- Mallowan, M. E. L. 1947. Excavations at Brak and Chagar Bazar. Iraq 9, 1-87+89-259+i+iv.

- Maloney, C. (ed.) 1976. The Evil Eye. New York, Columbia University Press.

- Maxwell-Stuart, P. G. (ed.) 2005. The Occult in Mediaeval Europe, 500-1500: A Documentary History. Basingstoke, Palgrave Macmillan.

- McCarthy, J. P. 2001. 'Magic' in the expression of identity in Antebellum Philadelphia: Non-Christian burial practices at the cemeteries of the First African Baptist Church. In Wallis, R. J. and Lymer, K. (eds.) A Permeability of Boundaries? New Approaches to the Archaeology of Art, Religion and Folklore. Oxford, J. \& E. Hedges: 41-45.

- Merrifield, R. 1987. The Archaeology of Ritual and Magic. London, Batsford.

- Murray, C. 1999. And Did Those Feet in Ancient Time...Feet and shoes as a material projection of the self. In Baker, P. Forcey, C. Jundi, S. and Witcher, R. (eds.) Trac 98: Proceedings of the Eighth Annual Theoretical Roman Archaeology Conference Leicester 1998. Oxford, Oxbow: 131-140.

- Nadel, S. F. 1954. Nupe Religion: traditional beliefs and the influence of Islam in a West African chiefdom. London, Routledge and Kegan Paul.

- Pococke, R. 1750. Travels through England. In Cartwright, J. J. (ed.) 1887. London, Nichols and Sons.

- Porter, E. 1969. Cambridgeshire Customs and Folklore. London, Routledge and Kegan Paul.

- Puckett, N. N. 1926. Folk Beliefs of the Southern Negro. New York, Negro University Press.

- Radford, E. \& Radford, M. A. 1948. Encyclopaedia of Superstitions. London, Hutchinson.

- Reay, B. 1985. Popular Culture in Seventeenth-Century England. London, Croom Helm.

- Riello, G. 2006. A Foot in the Past: Consumers, Producers and Footwear in the Long Eighteenth Century. Oxford, Oxford University Press.

- Schechner, R. 2002. Ritual and Performance. In Ingold, T. (ed.) Companion Encyclopedia of Anthropology. London, Routledge: 613-647.

- Scot, R. 1584. The Discoverie of Witchcraft. In Williamson, H. R. (ed.) 1964. London, Centaur Press. 
- Steiner, C. B. 2001. Rights of Passage: On the Liminal Identity of Art in the Border Zone. In Myers, F. R. (ed.) The Empire of Things: Regimes of Value and Material Culture. Santa Fe, School of American Research Press, and Oxford, James Currey: 207-231.

- Swann, J. 1996. Shoes Concealed in Buildings. Costume 30, 56-69.

- Thomas, K. 1971. Religion and the Decline of Magic: Studies in popular beliefs in sixteenth and seventeenth century England. London, Weidenfeld and Nicolson.

- Thomas, N. 1989. Material Culture and Colonial Power: Ethnological Collecting and the Establishment of Colonial Rule in Fiji. Man 24 (1), 41-56.

- Thomas, N. 1991. Entangled Objects: Exchange, Material Culture, and Colonialism in the Pacific. Cambridge, Harvard University Press.

- Thompson, M. 1979. Rubbish Theory: The creation and destruction of value. Oxford,

- Tilley, C. 1999. Metaphor and Material Culture. Oxford, Oxford University Press.

- Tilley, C. 2004. The Materiality of Stone: explorations in landscape phenomenology. Oxford, Berg.

- Tilley, C. 2006. Objectification. In Tilley, C. Keane, W. Küchler, S. Rowlands, M. and Spyer, P. (eds.) Handbook of Material Culture. London, Sage: 60-73.

- Wallis, R. J. and Lymer, K. (eds.) 2001. A Permeability of Boundaries? New Approaches to the Archaeology of Art, Religion and Folklore. Oxford, J. \& E. Hedges.

- Wingfield, C. 2010. A case re-opened: the science and folklore of a 'Witch's Ladder. Journal of Material Culture 15 (3), 302-322.

\section{Internet Resources}

- Hoggard, B. 2000. Apotropaios. http://www.apotropaios.co.uk/ (Accessed 02/03/2011)

- Textile Conservation Centre Foundation. 2010. Deliberately Concealed Garments Project. http://www.concealedgarments.org/ (Accessed 10/03/2011)

- Oxford English Dictionary. 2010. http://www.oed.com/ (Accessed 01/04/2011) 


\section{Biography}

Ceri Houlbrook is currently in the first year of her $\mathrm{PhD}$ in the Department of Archaeology, at the University of Manchester. She attained a First Class BA (Hons) in Classical Studies at the University of Edinburgh in 2008, and achieved a Distinction in her interdisciplinary MA, Constructions of the Sacred, the Holy and the Supernatural, at the University of Manchester in 2011. Her MA dissertation, 'The Suburban Boggart', a consideration of the survival and revival of folklore in an inner-city park in North Manchester, was awarded The Folklore Society President's Prize in October 2011. For her doctoral thesis, she is researching the revival of the ritual of 'coin-trees' in the British Isles. Her primary academic interest is the archaeology of folklore, specifically the folklore of the British Isles. 